\title{
Spiral Strand Cables Subjected to High Velocity Fragment Impact
}

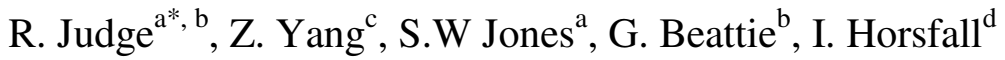 \\ ${ }^{a}$ Blast \& Impact Research Centre, School of Engineering, the University of Liverpool, L69 3GH, UK \\ ${ }^{\mathrm{b}}$ Arup, Liverpool, L3 9QJ, UK \\ ${ }^{\mathrm{c}}$ Centre for Low Impact Buildings, Faculty of Engineering and Computing, Coventry University, CV 5FB, UK \\ ${ }^{\mathrm{d}}$ Cranfield University, Shrivenham, SN6 8LA, UK
}

\begin{abstract}
Structural cables are widely adopted around the world in offshore construction, sports stadia, large scale bridges, Ferris wheels and suspended canopy and fabric structures. However, the robustness of such structures to blast or impact is uncertain with a particular concern related to the loss of a primary structural cable when damaged by high velocity blast fragmentation. This paper presents the first ever numerical and experimental study on commonly used high-strength steel spiral strand cables subjected to high velocity fragment impact. Spiral strand cables were impacted by $20 \mathrm{~mm}$ fragment simulating projectiles travelling at velocities between 200 and $1400 \mathrm{~m} / \mathrm{s}$. Complex 3D non-linear finite element models were developed and carefully compared with experimental tests. The penetration resistance of the cables and resultant damage were studied with respect to fragment impact velocity. It was found that for all the impact velocities, the fragment penetration depth was less than half of the cable diameter demonstrating a considerable amount of resilience. Considering the damage caused, the residual cable breaking strengths were estimated and found to be still higher than the minimum breaking load of an un-damaged cable. The numerical models were also able to reproduce the main features of the impact tests, including the extent of localised damage area, the fragment penetration depth and mode of individual wire failures, thus demonstrating their potential to be widely used in industry for structural resilience and robustness assessments by structural engineers.
\end{abstract}

Keywords: spiral strand cable, non-linear finite element method, fragment simulating projectile, impact, modified Johnson-Cook Model, Cockcroft-Latham, LS-DYNA

\section{Introduction}

Cable supported structural systems are widely adopted in offshore construction (e.g. deep water mooring systems), sports stadia roof structures, large scale bridges, Ferris wheels and suspended canopy and fabric structures. They offer economic and innovative structural solutions due to their optimum strength-to-weight ratio when compared to other structural systems e.g. reinforced concrete and steel framing systems. A great deal of research and development has been carried out over the years to better understand the physical behaviour of such systems, most of which has found its way into design guidelines and international codes of practice for use by the practicing engineer. Most of this work has focused on cables subjected to quasi- 
static axial loading conditions [1]. More recently, as a result of the geo-politically and environmentally turbulent environment we now live in, the robustness of such structures to highly transient loading conditions such as a blast or impact has come into question. A particular concern associated with cable supported structures is that of sudden cable loss leading to disproportionate damage or collapse of part or all the structure [2, 3 and 4]. Zoli and Steinhouse [5] assessed the vulnerability of the typical cable types used in cable-stayed and cable-suspended bridges, and highlighted that there are a number of potential mechanisms capable of inducing sudden cable loss, including the impact of explosively formed fragments travelling at high velocity as depicted in Fig. 1

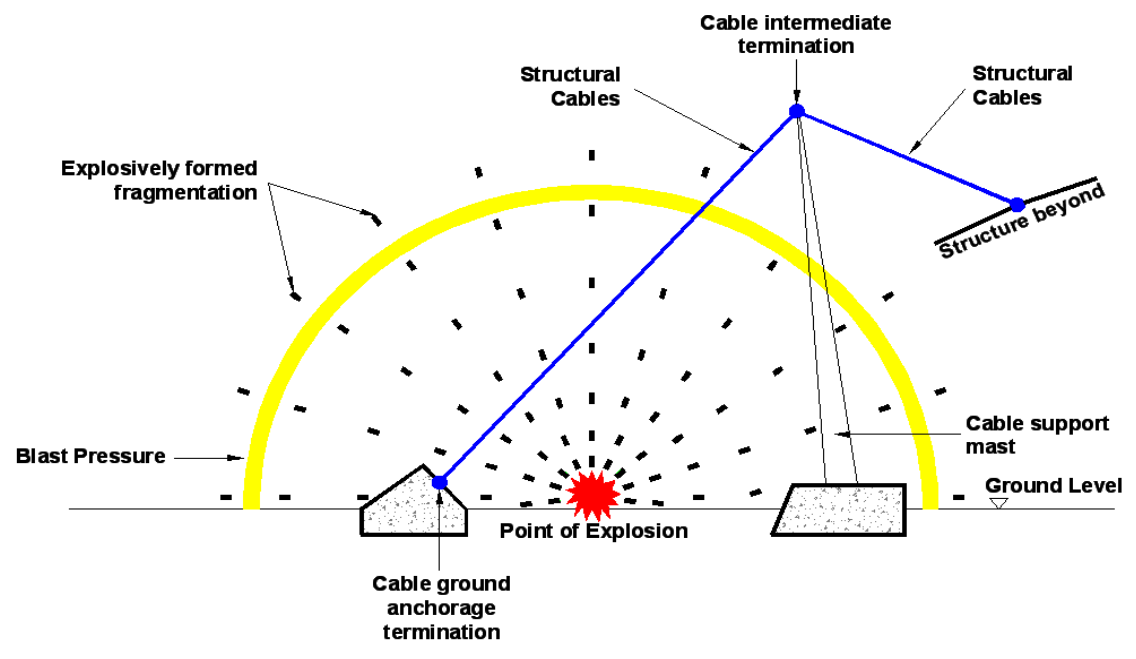

Fig. 1 Problem Schematic

The work presented in this paper forms part of a larger research programme to investigate the overall robustness of cable supported structures in the event of sudden single or multiple cable loss and is largely supported by industry due to the lack of fundamental guidance available. The primary focus of this paper is to develop a better understanding, via an initial study, of the levels of damage structural cables can sustain when subjected to high velocity fragment impact and whether or not such damage has the potential to induce sudden cable loss. This initial study is the first of its kind and thus this paper is a first step forward in understanding the robustness of such structures to highly transient loading conditions.

The approach taken to conduct the study was a combination of laboratory tests and numerical simulations. The geometric details and mechanical properties of the cables studied are outlined in Section 2. In the absence of real fragment data from an accidental or malicious explosion, the fragments used in the impact tests were standard $20 \mathrm{~mm}$ fragment simulating projectiles (FSP) [6]. 
The testing conducted in this study was limited but nevertheless provided a good initial insight into the sort of damage that might be induced in a structural cable when subjected to fragment impact at velocities ranging from 200 to $1400 \mathrm{~m} / \mathrm{s}$ (sub-ordinance to ordinance range). In practice, the cables would be subjected to an axial tension before and after impact. However, due to safety restrictions within the firing range related to the levels of pre-stress required to achieve a working tension load, the cables could not be pre-tensioned and further tests are planned to study the implications of this on the impact damage zone.

Alongside the testing, full 3D non-linear finite element (FE) models of the cables were developed in LSDYNA [7], with careful considerations given to the complex geometry of the cables, inter-wire contact mechanics, cable-end boundary conditions and appropriate material modelling. The numerical and experimental results were carefully compared, with particular attention paid to the localised damage area, the fragment penetration depth, the number of heavily indented and totally fractured wires, resulting in an estimation of the residual cable breaking load post impact.

This paper is organised as follows: In Section 2, the spiral strand cable physical and mechanical properties are presented along with an estimative equation later used to predict residual cable breaking loads. In Section 3, the experimental test set-up is highlighted and the results of the impact tests are presented. This includes a qualitative metallurgical study of the wire fracture and damage mechanics using scanning electron microscopy (SEM) and an evaluation of cable damage. In Section 4, the formulation of finite element models of the cable impact tests is presented outlining the boundary conditions, element formulation, contact mechanics and constitutive relations used to represent the material behaviour on impact. Section 5 compares the results of the experimental testing and numerical simulations and highlights areas where further research and development is required. Section 6 concludes the findings of the study.

\section{Spiral strand cables}

Spiral strand cables are commonly used as backstay and main support cables in the structural systems described at the start of Section 1. They comprise many groups of individual high strength round steel wires. The wires are manufactured from high carbon steel with nominal tensile strengths in the range of $1570 \mathrm{MPa}$ to $1960 \mathrm{MPa}[8,9]$. Their high tensile strength is attributed to the wire drawing process (i.e. cold working) and heat treatment processes along with the inclusion of small amounts of chromium, silicon and vanadium. The wires are hot-dip galvanized for corrosion resistance before they are used to make-up a structural cable. The cables are built-up using circumferential layering in which the wires in each layer are spirally wound around a central wire and spun in opposite directions. This minimises both residual torque and wire de-coiling as a result of the elastic stress induced in the wires during the winding process. A typical spiral strand cable is shown in Fig. 2 [10]. 

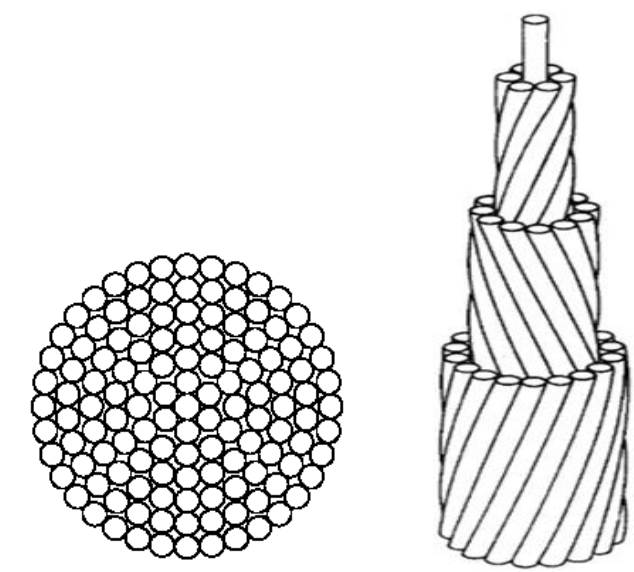

Fig. 2 A typical cross section and side elevation of a spiral strand cable [10]

Uniaxial tensile strength tests on individual wires are normally carried out by the cable manufacturer to obtain an engineering stress-strain relation which is used to determine the basic mechanical properties such as the Young's modulus $(E)$, yield strength $\left(\sigma_{0.2}\right)$ and ultimate tensile strength (UTS) of the wire. A measure of wire ductility is also established from the wire elongation and reduction in cross-sectional area at failure. Typical test data provided by the cable manufacturer, Bridon International Ltd, for both $1570 \mathrm{MPa}$ and $1770 \mathrm{MPa}$ UTS wires of $5 \mathrm{~mm}$ diameter are listed in Table 1, where $0.2 \%$ proof stresses are given because usually no obvious yielding points can be seen in the stress-strain relations.

Table 1 Typical mechanical properties of $1570 \mathrm{MPa}$ and $1770 \mathrm{MPa}$ wires

\begin{tabular}{ccccccc}
\hline $\begin{array}{c}\text { Wire Grade } \\
(\mathrm{MPa})\end{array}$ & $\begin{array}{c}\text { Wire } \\
\text { Diameter } \\
(\mathrm{mm})\end{array}$ & $\begin{array}{c}\text { Breaking } \\
\text { Load }(\mathrm{kN})\end{array}$ & $\begin{array}{c}0.2 \% \text { Proof } \\
\text { Stress } \\
\sigma_{0.2}(\mathrm{MPa})\end{array}$ & $\begin{array}{c}\text { Ultimate Tensile } \\
\text { Strength }(\mathrm{MPa})\end{array}$ & $\begin{array}{c}\text { Elongation } \\
\%\end{array}$ & $\begin{array}{c}\text { Area } \\
\text { Reduction \% }\end{array}$ \\
\hline 1570 & 5 & 34.11 & 1435 & 1737 & 8.79 & 23.26 \\
1770 & 5 & 37.34 & 1623 & 1902 & 10.85 & 34.41
\end{tabular}

The cable chosen for investigation in this study is a $60 \mathrm{~mm}$ diameter spiral strand which consists of 120wires with a nominal UTS of $1770 \mathrm{MPa}$. It has one straight central core wire and six outer layers of wires, with each layer spirally wound in opposite directions over one another around the central wire. The spiral angle, known as the lay angle, is related to the lay length of the individual wires. The lay length describes the distance after which a wire reappears at the same angular position along the longitudinal axis of the cable. It is different for each layer of wires as the diameter of each layer increases. The breaking strength of the cable is dependent on the lay length, being lower for shorter lay lengths and greater for longer lay lengths. The geometric details of the cable are listed in Table 2 . 
Table 2 Geometric details of the $60 \mathrm{~mm}$ diameter spiral strand cable

\begin{tabular}{cccc}
\hline Layer & No. of wires & Wire diameter $(\mathrm{mm})$ & Lay length $(\mathrm{mm})$ \\
\hline Central wire & 1 & 5.8 & N/A \\
1 & 7 & 4.3 & 150 \\
2 & 17 & 3.2 & 210 \\
3 & 14 & 5.4 & 320 \\
4 & 21 & 5.0 & 420 \\
5 & 27 & 5.0 & 520 \\
6 & 33 & 5.0 & 620
\end{tabular}

The common value for most design standards e.g. $[11,12]$ is the minimum breaking load (MBL) which is the load that will always be achieved in a breaking load test. The MBL is also referred to in some design standards as the characteristic breaking load or the nominal cable strength and it is a value that is quoted by cable manufacturers in technical literature. The minimum breaking load is derived using partial safety factor philosophy which is also referred to as the Load Resistance Factor Design. The design resistance $Z_{R, d}$ of a cable subjected to a static load is calculated by dividing the MBL by the partial safety factor of $1.5 \mathrm{x}$ $1.1=1.65$ hence reducing the breaking load by $45 \%$.

Equation 2.1 is provided in [11] for estimating the minimum breaking force $\left(F_{\min }\right)$ which is the same as the MBL.

$F_{\min }=\frac{d^{2} R_{r} K}{1000} \quad[\mathrm{kN}] \quad(2.1)$

where $d$ is the diameter of the cable in $\mathrm{mm}$ (60 $\mathrm{mm}$ in the present study), $K$ is the breaking force factor (derived below) and $R_{r}$ is the grade of the wires in MPa (1770 MPa in the present study).

The breaking force factor is an empirical value used in the determination of the minimum breaking force and is given by Equation 2.2. It is used to account for the fill factor (ratio of wire/air voids) and load loss resulting from the layer lay lengths and lay angles

$K=\frac{\pi f k}{4} \quad(2.2)$

where $f$ is the fill factor for the rope or cable and $k$ is the spinning loss factor. The fill factor is the ratio of the sum of nominal metallic cross-sectional areas of all wires in a cable $(A)$ and the circumscribed area $\left(A_{u}\right)$ 
of the cable based on its nominal diameter $(d)$. The spinning loss factor is a reduction factor for cable construction included in the breaking force factor. The fill factor for spiral strands is 0.73 taken from Table 2.2 in [11]. The spinning loss factor $k$ is not stated in the code. However, given that it is a loss factor, the value cannot be greater than unity. On that basis $K=0.5735$ and $F_{\min }=3654 \mathrm{kN}$ using the above parameters. Equation 2.3 is provided by [11] for calculating $A_{m}$ which is the nominal metallic crosssectional area of the cable.

$A_{m}=\frac{\pi d^{2}}{4} f$

As above, taking $f$ as $0.73, A_{m}=2064 \mathrm{~mm}^{2}$ for a $60 \mathrm{~mm}$ diameter cable. When multiplied by $R_{r}(1770)$ the same breaking load is derived, $F_{\min }=3654 \mathrm{kN}$.

Based on the above, Equation 2.4 can be used to estimate a reduced cable breaking load after impact.

$F_{\text {min reduced }}=\left(A_{m}-A_{N d} R_{r} k\right)$

where $A_{N d}$ is the area of totally fractured and heavily indented wires for each fragment impact velocity. Wires that have not totally fractured through their cross-section will have reduced load carrying capacity if heavily indented. This has also been accounted for via a balance where if there is a reduction in wire crosssection $\geq 20 \%$ (through indentation) the wire area was also discounted from the calculation. This is discussed further in Section 5 where reduce cable breaking loads are estimated.

\section{Experimental Impact Tests}

\subsection{Test set-up}

Six 1-m long cable samples provided by Bridon International Ltd were tested using the powder gun shown in Fig. 3a at Bashforth Laboratories, UK. The samples were mechanically fitted with a wrap-around steel coil at both ends to mimic the end conditions when socketed into steel end-terminations. The length of the coils with respect to the cable sample lengths was approximately $300 \mathrm{~mm}$. The cable samples were clamped to a single test frame as shown in Fig. $3 b$. 


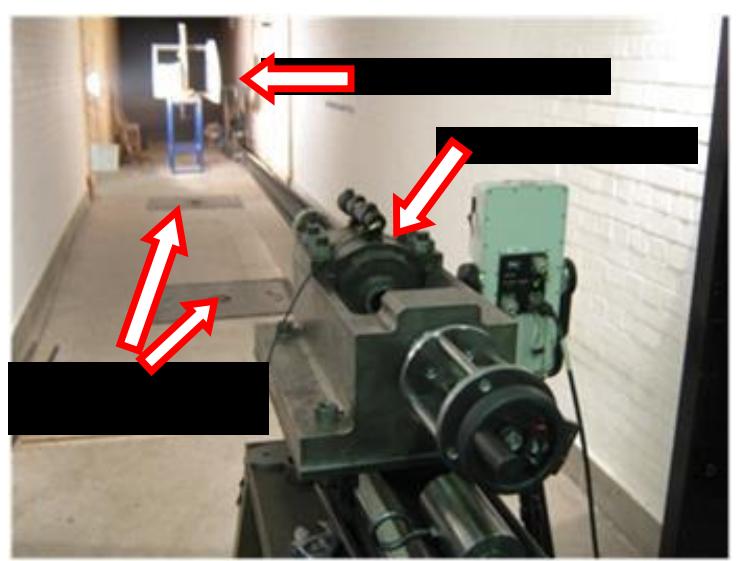

(a) powder gun

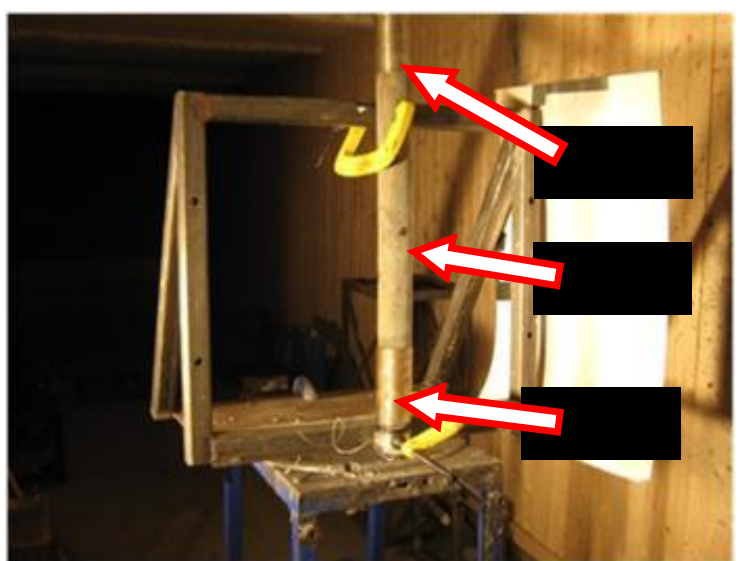

(b) test frame

Fig 3 Typical test set-up

The $20 \mathrm{~mm}$ FSPs were fired from an Oerlikon Powder Gun with a $20 \mathrm{~mm}$ barrel, fitted to UK No.4 proof housing. The cartridge case was $20 \mathrm{~mm}$ x $128 \mathrm{~mm}$ and filled with 10-45g of Vihtavuori N160/165 propellant for firing. The FSPs were manufactured from $4340 \mathrm{H}$ steel with a hardness and geometry as described in MIL-DTL-46593B [6]. The FSPs are designed to simulate fragments which might be generated by an explosive device such as an artillery shell [13]. In this study, they are considered to be a sensible representative of the harder fragments (nuts, bolts, buckles and door locking mechanisms) which may be launched from a vehicle borne improvised explosive device. Their use provides a reproducible impact at a selected site on the target rather than the variable geometry and placement of fragments that would result from an explosive device.

The velocities were recorded at two points in transit using a Weibul W700 Doppler Radar optical measurement system located within the floor of the firing range. The velocities considered for zero obliquity impacts were $V_{i}=1328 \mathrm{~m} / \mathrm{s}, 680 \mathrm{~m} / \mathrm{s}, 580 \mathrm{~m} / \mathrm{s}, 501 \mathrm{~m} / \mathrm{s}, 360 \mathrm{~m} / \mathrm{s}$ and $297 \mathrm{~m} / \mathrm{s}$, respectively. A single test was also conducted where the impact angle was set to $45^{\circ}$ by horizontal rotation of the sample as shown in Fig. 4. In this instance, the fragment velocity was set at a mid-point value of $640 \mathrm{~m} / \mathrm{s}$. 


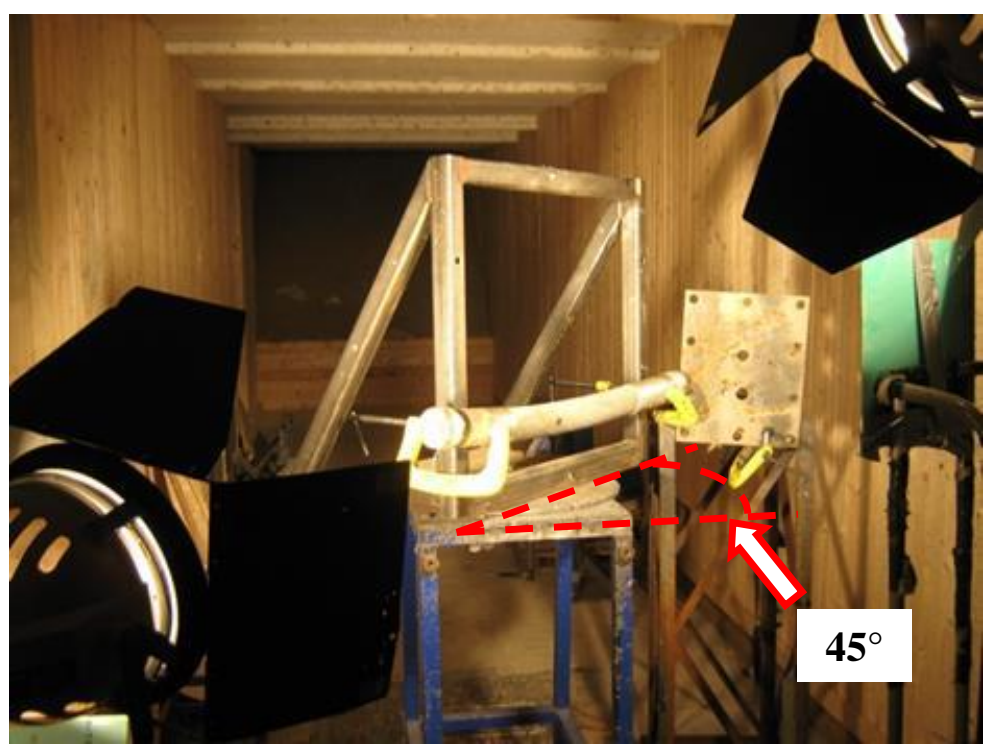

Fig 4 Sample rotation for $45^{\circ}$ fragment impact at $V_{i}=640 \mathrm{~m} / \mathrm{s}$

A Phantom V12 monochrome high speed video camera was used to capture each of the impact events. The camera was located just to the left of the test rig out of sight in Fig. 4. Given the limitation on samples provided and the preliminary nature of the testing, no repeat tests were conducted.

\subsection{Test results}

Figs. 5 and 6 show the damaged cables after impact for all velocities considered. In all the tests the fragments did not perforate the cables and significant penetration was observed only for $V_{i}=1328 \mathrm{~m} / \mathrm{s}$ and $680 \mathrm{~m} / \mathrm{s}$. All the damage was localised to an impact zone of approximately $200-250 \mathrm{~mm}$ in length along the samples. 


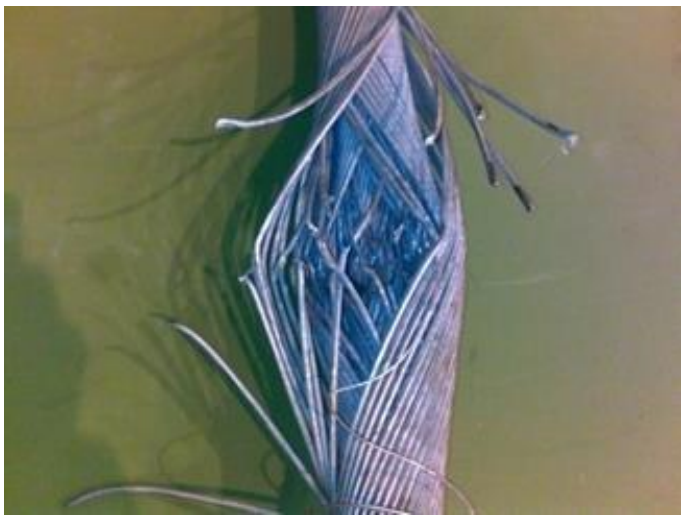

(a) $V_{i}=1328 \mathrm{~m} / \mathrm{s}$

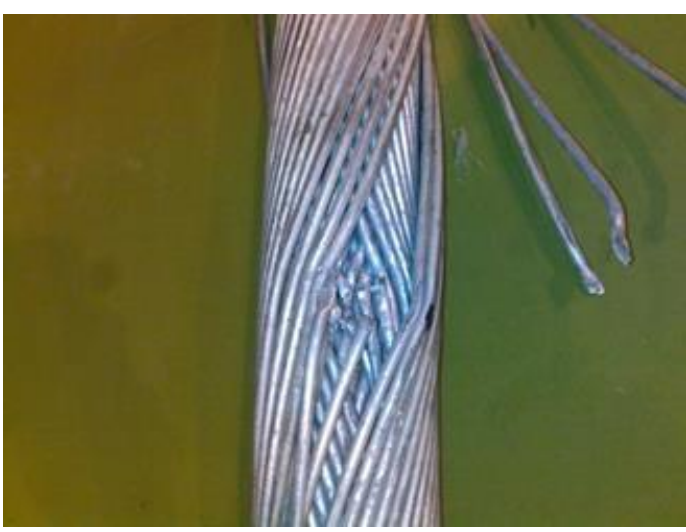

(c) $V_{i}=580 \mathrm{~m} / \mathrm{s}$

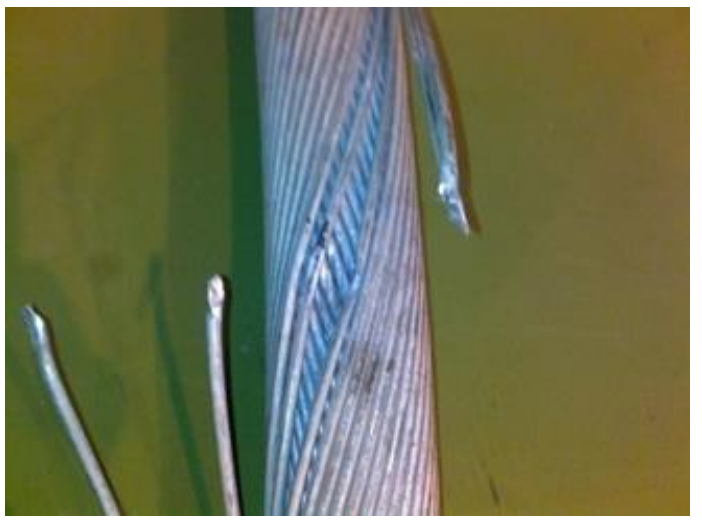

(e) $V_{i}=360 \mathrm{~m} / \mathrm{s}$

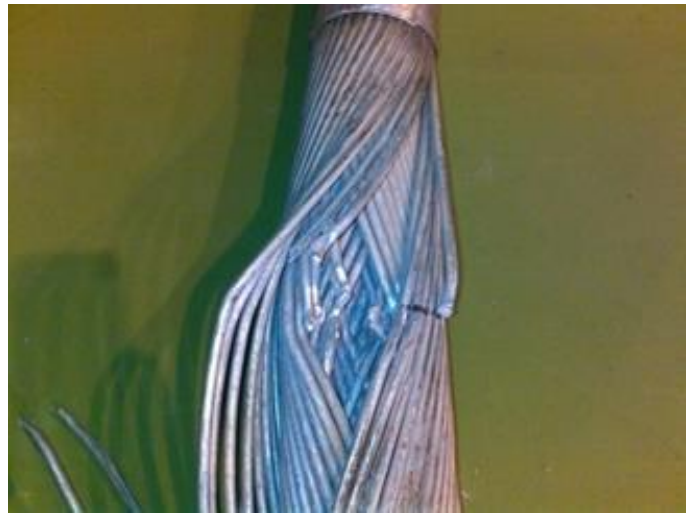

(b) $V_{i}=680 \mathrm{~m} / \mathrm{s}$

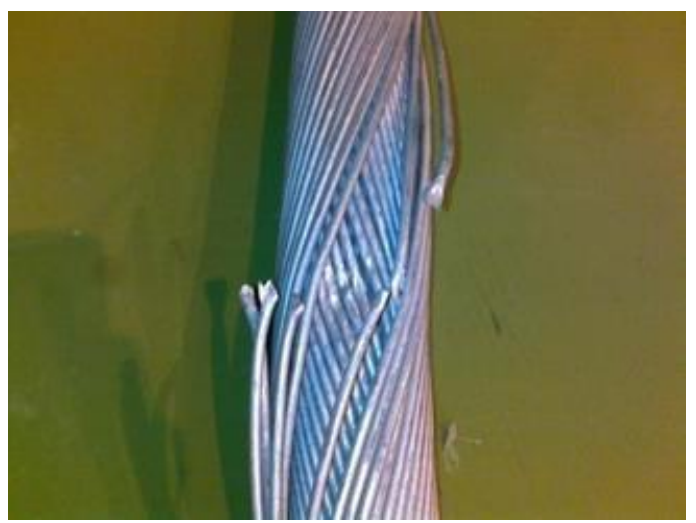

(d) $V_{i}=501 \mathrm{~m} / \mathrm{s}$

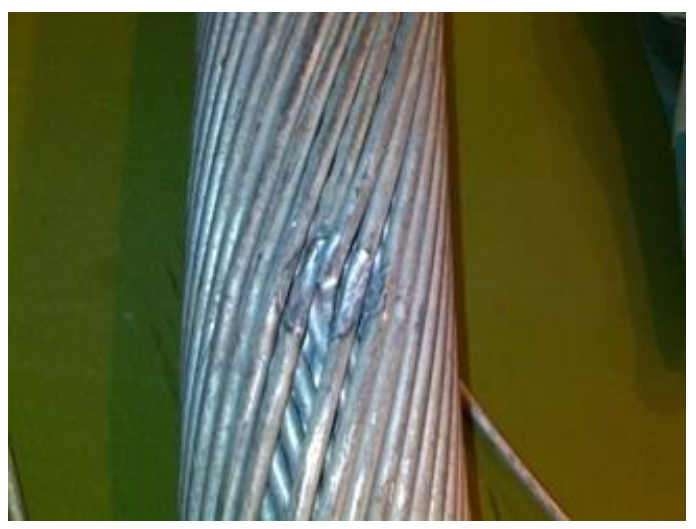

(f) $V_{i}=297 \mathrm{~m} / \mathrm{s}$

Fig. 5 Fragment damaged cables (angle of impact $=0^{\circ}$ ) 


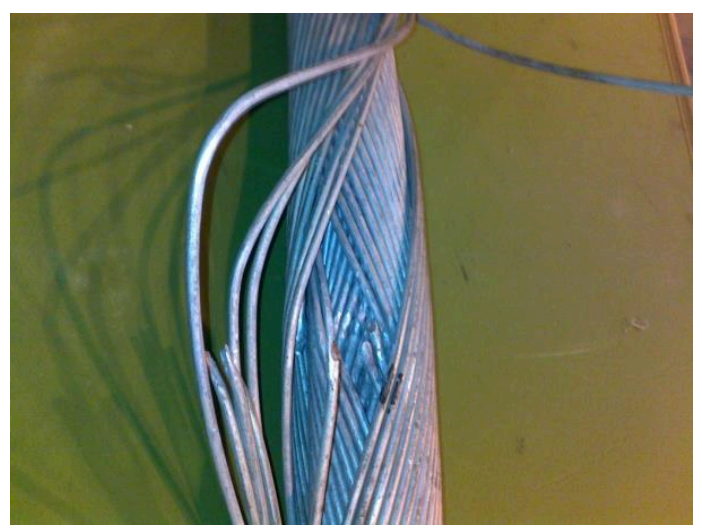

Fig. 6 Fragment damaged cables at $V_{i}=640 \mathrm{~m} / \mathrm{s}\left(\right.$ angle of impact $\left.=45^{\circ}\right)$

Significant wire splay (horizontal wire translation) at the impact zone was observed for the highest impact velocities $\left(V_{i}=1328 \mathrm{~m} / \mathrm{s}\right.$ and $680 \mathrm{~m} / \mathrm{s}$ at an impact angle of $0^{\circ}$ and $640 \mathrm{~m} / \mathrm{s}$ at an impact angle of $\left.45^{\circ}\right)$. Wire flattening was also observed at the point of impact. It was found from post-impact inspections that a number of wires at the ends of the cable samples had been pulled through the cable-end steel coils on impact. This occurred in all tests but was most severe for $V_{i}=1328 \mathrm{~m} / \mathrm{s}$ and $680 \mathrm{~m} / \mathrm{s}$. This is shown in Fig. 7 and is not representative of what would happen if the ends of the cables were fully terminated within socketed terminations where all wires would be anchored in a zinc cone.

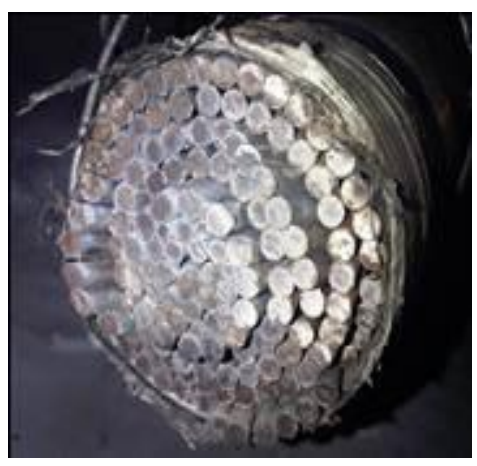

(a) $1328 \mathrm{~m} / \mathrm{s}$

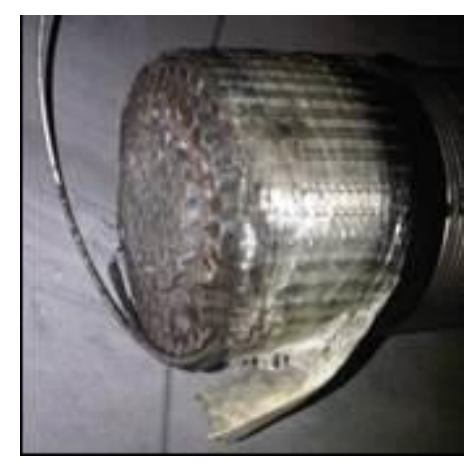

(b) $680 \mathrm{~m} / \mathrm{s}$

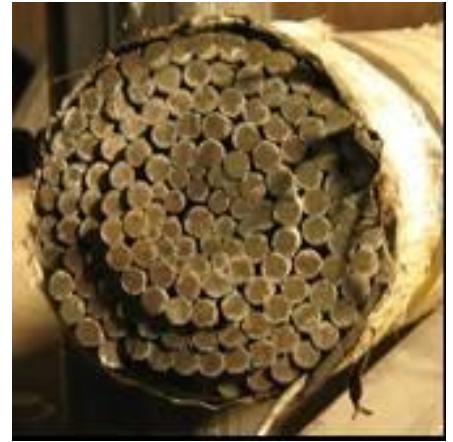

(c) $640 \mathrm{~m} / \mathrm{s}$

Fig. 7 Wires pulled through coils at ends of cable samples

Stills of each impact are shown in Fig. 8, captured from the high speed videos. At $V_{i}=1328 \mathrm{~m} / \mathrm{s}$ there was a small shock on impact hence making it very difficult to observe the response of the cable during penetration. All that was seen throughout the impact process was a large cloud of dust and fragmentation. 


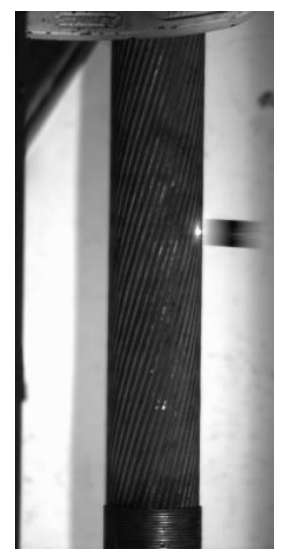

(a) $0 \mathrm{~ms}$

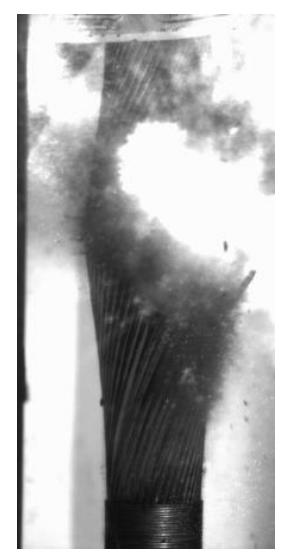

(b) $10 \mathrm{~ms}$

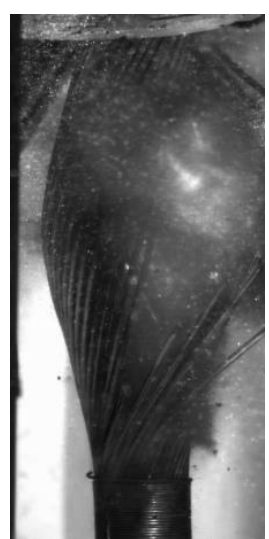

(c) $30 \mathrm{~ms}$

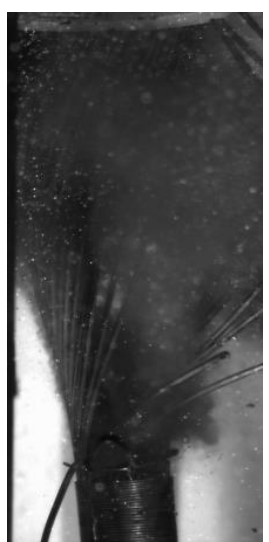

(d) $60 \mathrm{~ms}$

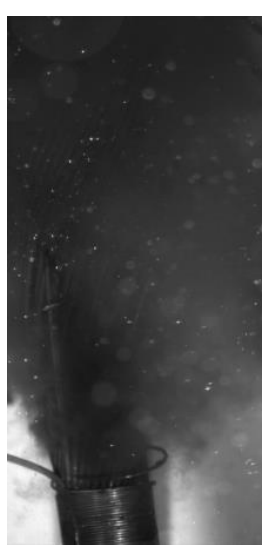

(e) $200 \mathrm{~ms}$ $V_{i}=1328 \mathrm{~m} / \mathrm{s}$, angle of impact $=0^{\circ}$

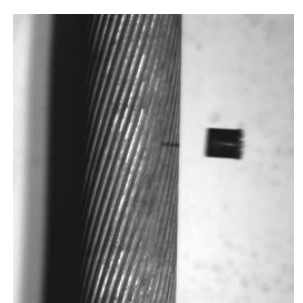

(f) $0 \mathrm{~ms}$

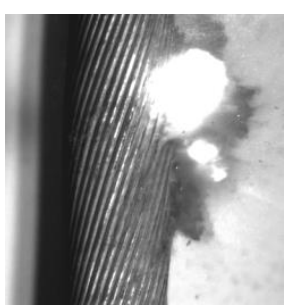

(g) $10 \mathrm{~ms}$

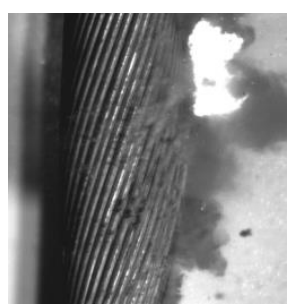

(h) $30 \mathrm{~ms}$

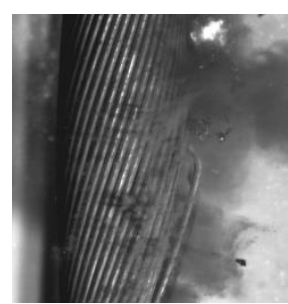

(i) $60 \mathrm{~ms}$

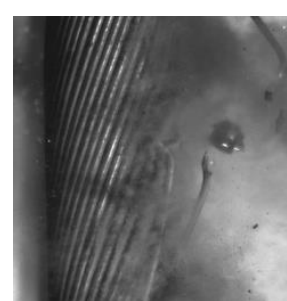

(j) $200 \mathrm{~ms}$

$V_{i}=680 \mathrm{~m} / \mathrm{s}$, angle of impact $=0^{\circ}$

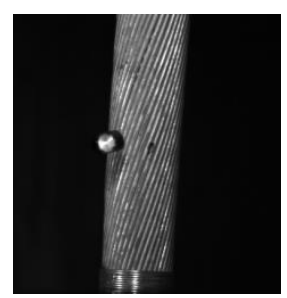

(k) $0 \mathrm{~ms}$

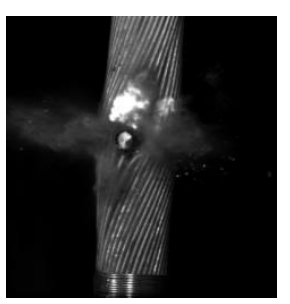

(l) $10 \mathrm{~ms}$

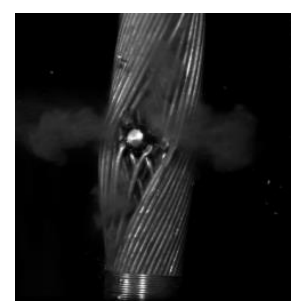

(m) $30 \mathrm{~ms}$

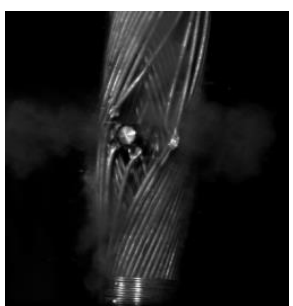

(n) $60 \mathrm{~ms}$

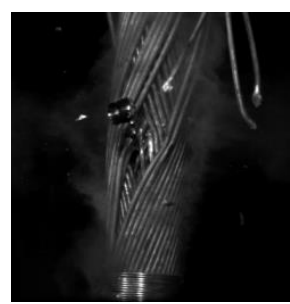

(o) $200 \mathrm{~ms}$

$V_{i}=580 \mathrm{~m} / \mathrm{s}$, angle of impact $=0^{\circ}$

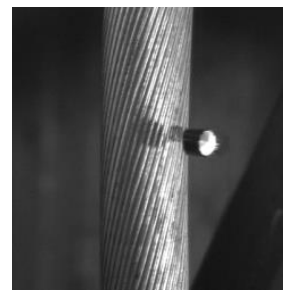

(p) $0 \mathrm{~ms}$

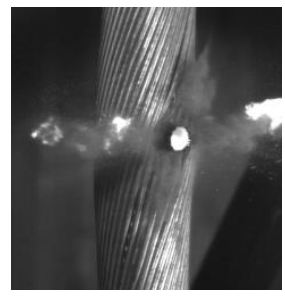

(q) $10 \mathrm{~ms}$

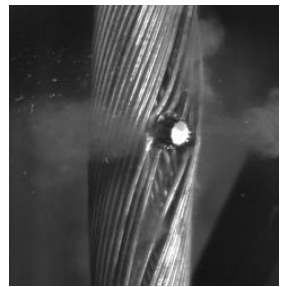

(r) $30 \mathrm{~ms}$

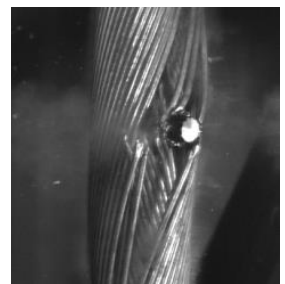

(s) $60 \mathrm{~ms}$

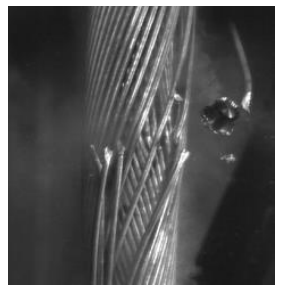

(t) $200 \mathrm{~ms}$ $V_{i}=501 \mathrm{~m} / \mathrm{s}$, angle of impact $=0^{\circ}$ 


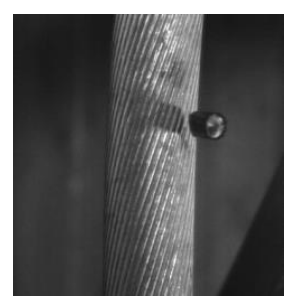

(q) $0 \mathrm{~ms}$

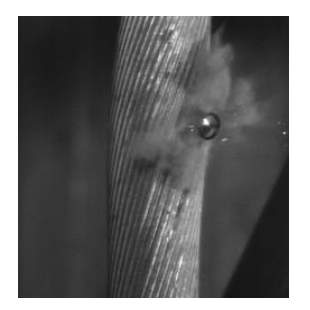

(r) $10 \mathrm{~ms}$

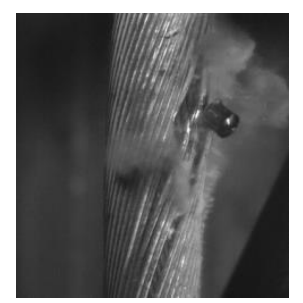

(s) $30 \mathrm{~ms}$

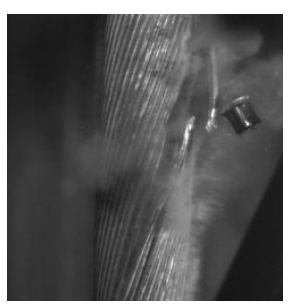

(t) $60 \mathrm{~ms}$

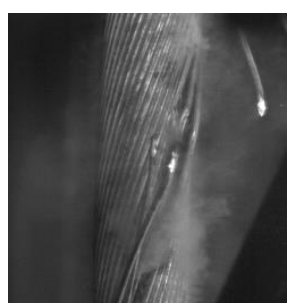

(u) $200 \mathrm{~ms}$

$V_{i}=360 \mathrm{~m} / \mathrm{s}$, angle of impact $=0^{\circ}$

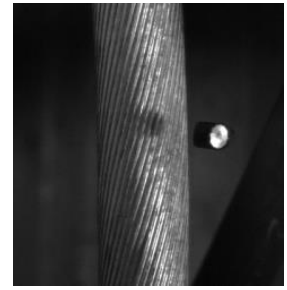

(v) $0 \mathrm{~ms}$

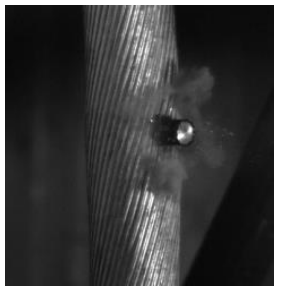

(w) $10 \mathrm{~ms}$

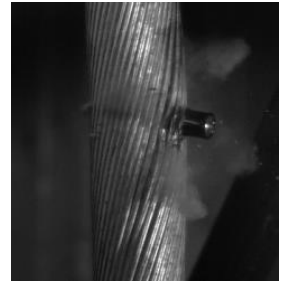

(x) $30 \mathrm{~ms}$

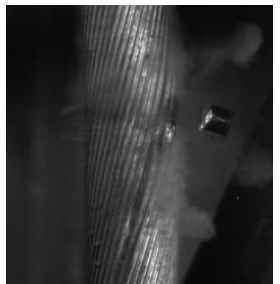

(y) $60 \mathrm{~ms}$

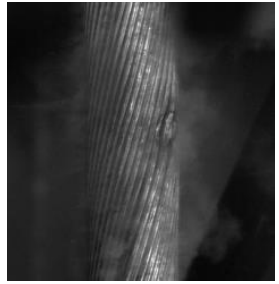

(z) $200 \mathrm{~ms}$

$V_{i}=297 \mathrm{~m} / \mathrm{s}$, angle of impact $=0^{\circ}$

Fig. 8 Fragment impact damage for all zero-obliquity FSP impacts

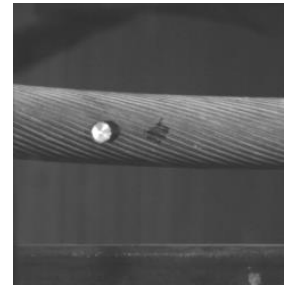

(a) $0 \mathrm{~ms}$

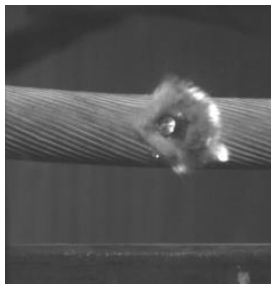

(b) $10 \mathrm{~ms}$

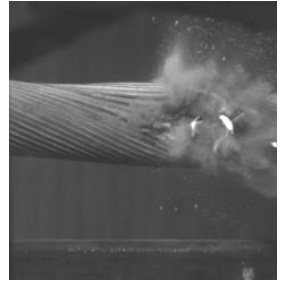

(c) $30 \mathrm{~ms}$

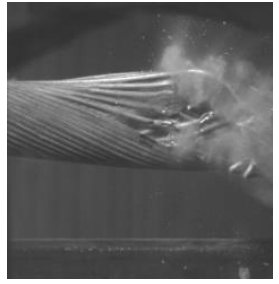

(d) $60 \mathrm{~ms}$

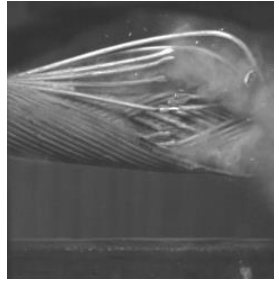

(e) $200 \mathrm{~ms}$

Fig. 9 Fragment impact damage at $V_{i}=640 \mathrm{~m} / \mathrm{s}$, angle of impact $=45^{\circ}$

As seen in Fig. 8, the fragments impact the cables normal to the surface, penetrate and fracture wires before rebounding. At an impact angle of $45^{\circ}$ the fragment induces a drag in the wires on the periphery as indicated in Fig. 9 (e).

The global cable displacement on impact was negligible. This is considered to be a result of the fragment impact velocity vs bending stiffness and inertia of the 1-m long $60 \mathrm{~mm}$ spiral strand samples.

\subsection{Wire failure mechanisms}

The individual wire failure mechanisms are complex. Based on a visual inspection, the dominant failure mode appears to be a flattening to breakage mechanism. This failure mode is believed to be a combination of initial compression (squashing) and shear eventually transitioning to tensile failure as the wire is displaced by the fragment. Fig. 10 shows close up images of the failed wires for zero obliquity impacts. 


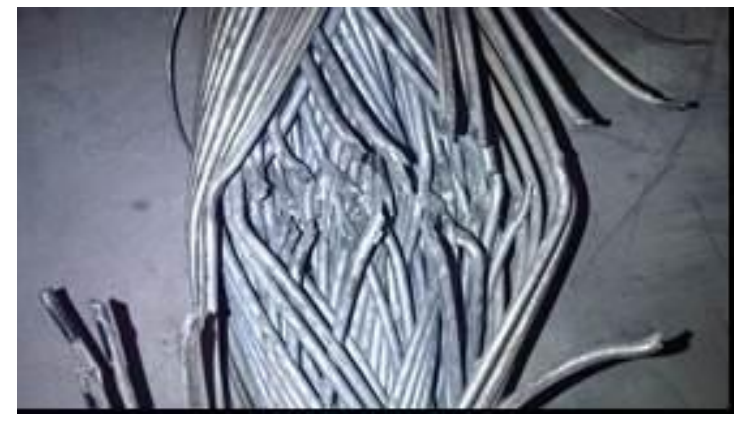

(a) Wire failure modes for $V_{i}=1328 \mathrm{~m} / \mathrm{s}$

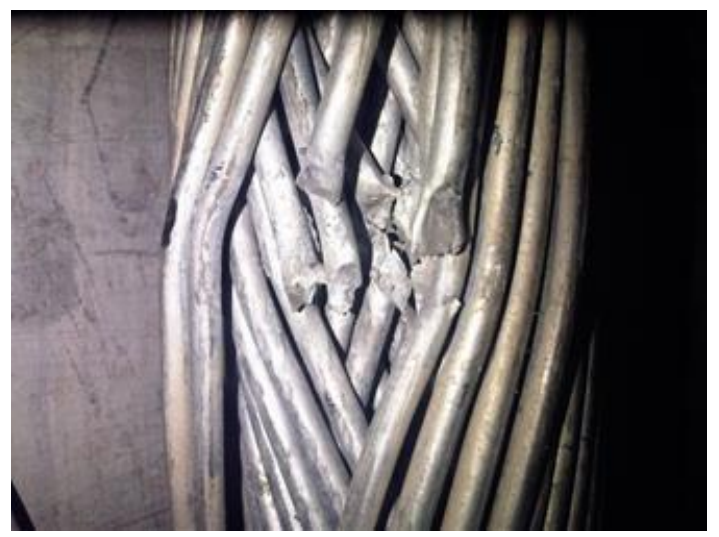

(c) Wire failure modes for $V_{i}=501 \mathrm{~m} / \mathrm{s}$

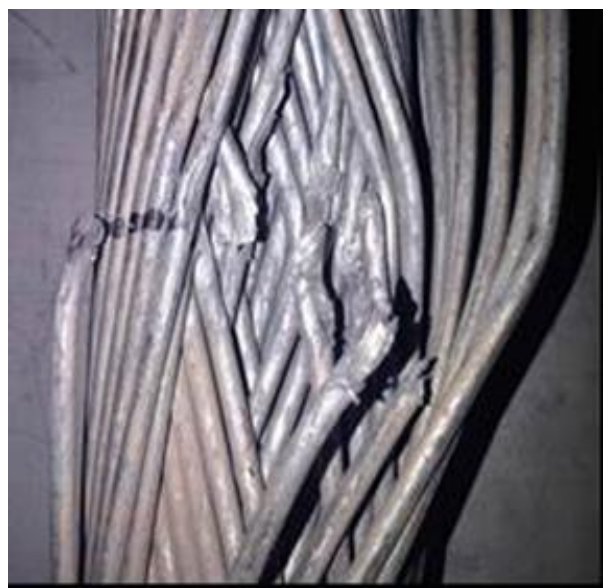

(b) Wire failure modes for $V_{i}=680 \mathrm{~m} / \mathrm{s}$

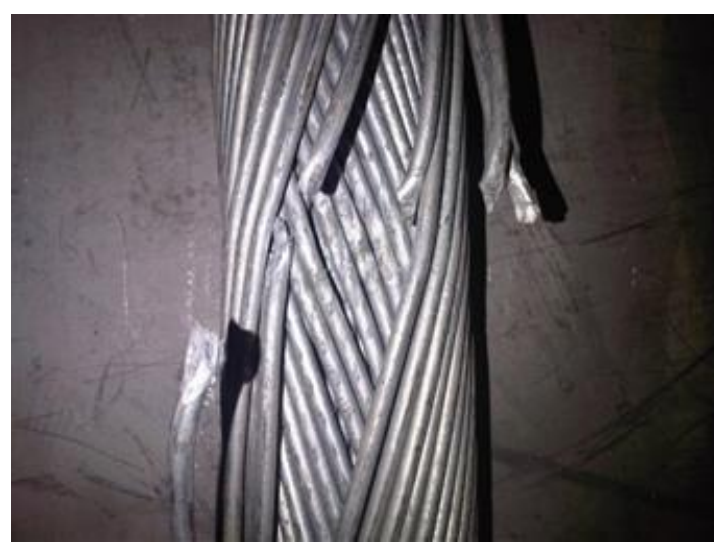

(d) Wire failure modes for $V_{i}=360 \mathrm{~m} / \mathrm{s}$

Fig. 10 Wire failure modes

\subsection{Metallurgical investigation}

To further understand the wire failure modes, a metallurgical assessment was carried out on a number of fractured wires taken from the damaged cable samples. Fig. 11 shows the central region of a fractured wire taken from the cable subjected to $V_{i}=1328 \mathrm{~m} / \mathrm{s}$. The images were captured using a scanning electron microscope (SEM) at different magnification scales. The failure mechanisms appear to be complex and involve a combination of compression, smearing, tearing and shear with associated ductile flow lines. 


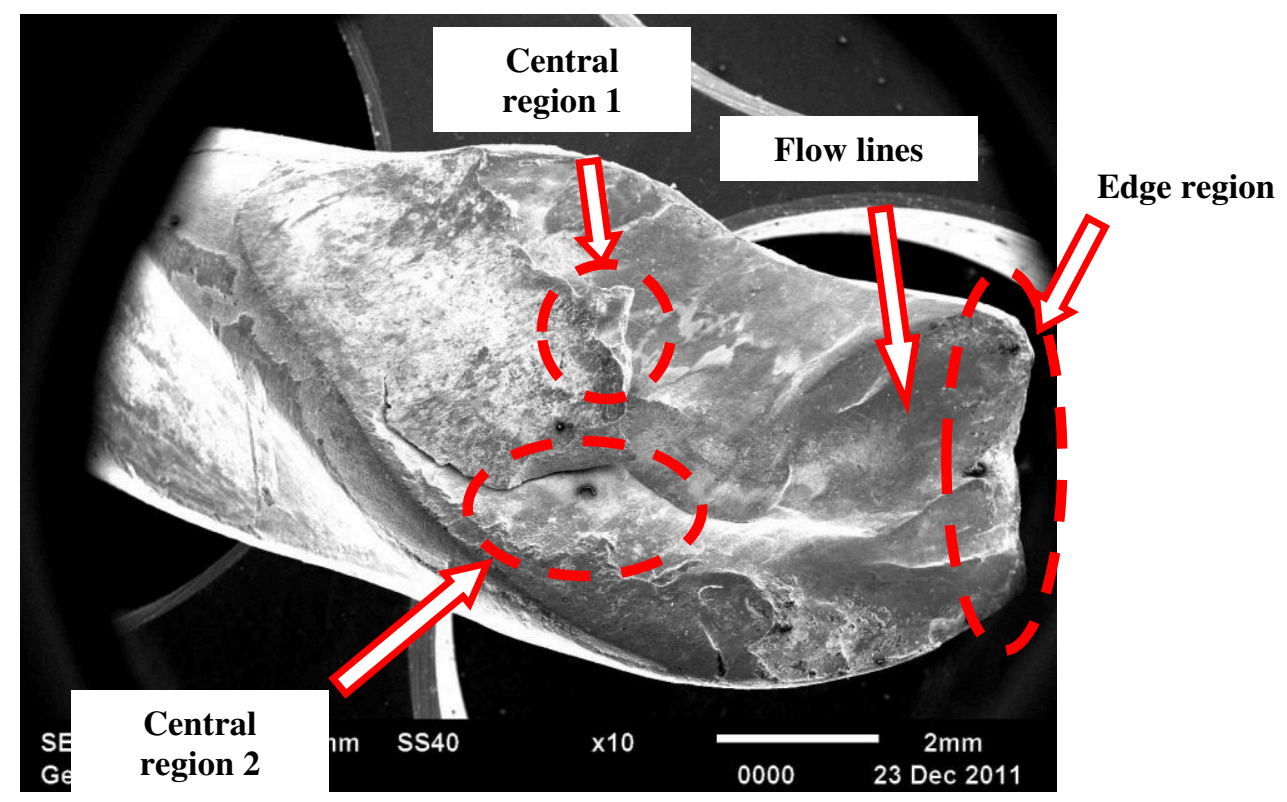

(a) Overall wire damage: $V_{i}=1328 \mathrm{~m} / \mathrm{s}$ (SEM $10 \mathrm{x}$ mag.)

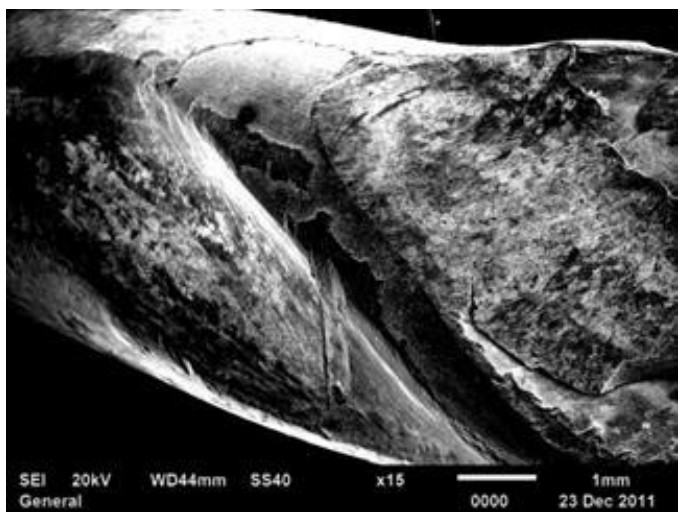

(b) Overall damage: $V_{i}=1328 \mathrm{~m} / \mathrm{s}$

(SEM $15 \mathrm{x}$ mag.)

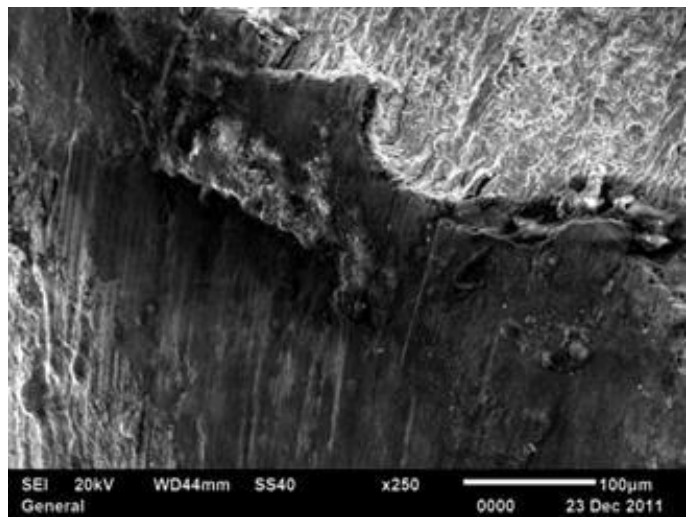

(c) Central region 1: $V_{i}=1328 \mathrm{~m} / \mathrm{s}$

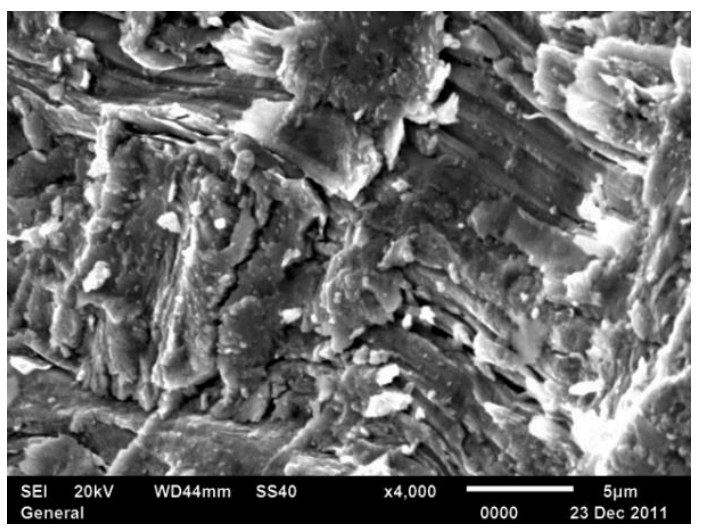

(d) Central region 1: $V_{i}=1328 \mathrm{~m} / \mathrm{s}$ (SEM $4000 \mathrm{x}$ mag.)

Fig. 11 SEM inspection of fractured wire for $V_{i}=1328 \mathrm{~m} / \mathrm{s}$ 
Fig. 12 shows the ductility of the fracture surface. This is indicated by the smearing and dimpled appearance caused by ductile tearing. The dimples form by a process referred to as Microvoid Coalescense (MVC) where voids nucleate (initiate), grow, and coalesce to develop the final fracture. In the testing this will have occurred very quickly and possibly at high temperature.

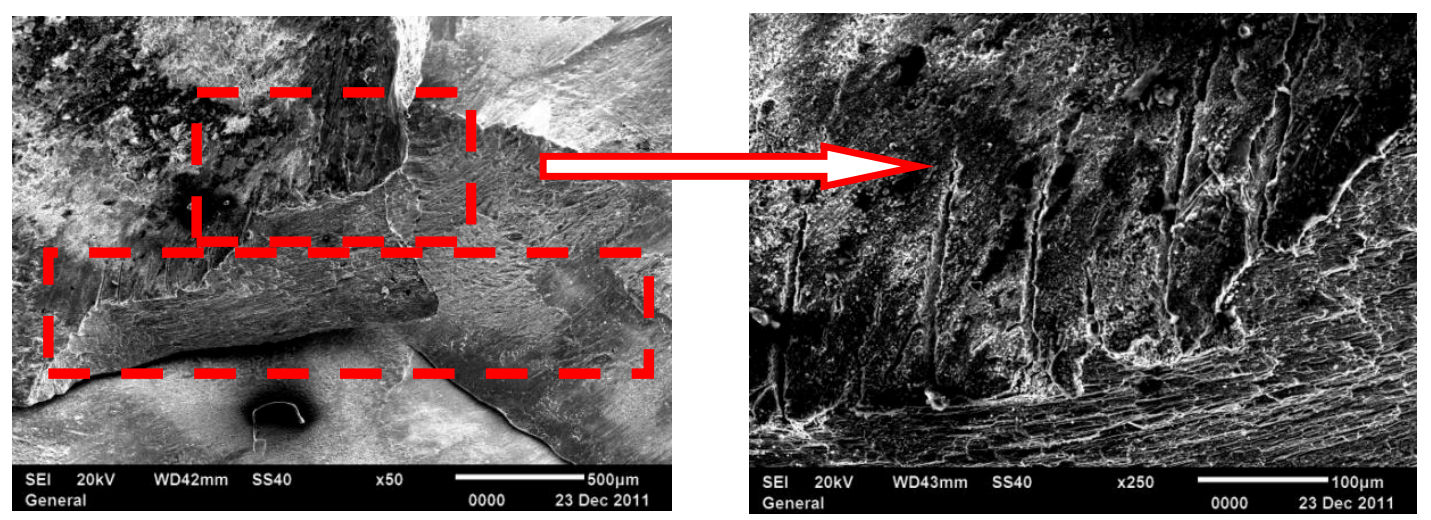

(a) Central region 2: $V_{i}=1328 \mathrm{~m} / \mathrm{s}$

(b) Central region 2: $V_{i}=1328 \mathrm{~m} / \mathrm{s}$

(SEM $50 \mathrm{x}$ mag.)

(SEM $250 \mathrm{x}$ mag.)

Fig. 12 SEM inpsection of slip-plane cracking on central region 2 of fractured wire for $V_{i}=1328 \mathrm{~m} / \mathrm{s}$

Fig. 12 shows what appears to be interlayer slip as indicated by the overlapping planes at the bottom of Fig. 12a. The slip appears to have a well-defined smoothed edge with a clear separation gap. This possibly suggests that it may not be slip but ductile thinning of overlapping material which has at that location. Fig. $12 \mathrm{~b}$ shows some ductile crack growth along a shear plane which has possibly been caused by smear dragging along the edge as indicated by the elongated dimples.

Fig. 13 shows the ductile flow of the material and clearly indicates the smearing lines induced by the fragment on impact. 


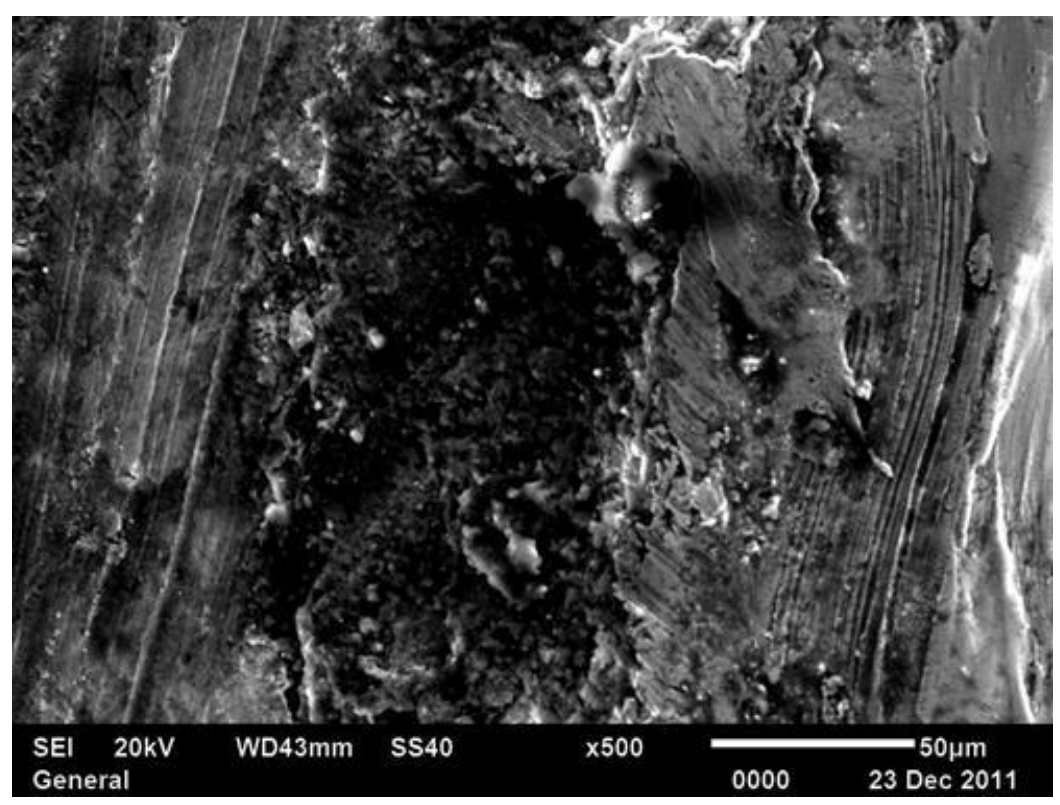

Fig. 13 Typical smearing of microstructure on impact on central region 2 of fractured wire for $V_{i}=1328 \mathrm{~m} / \mathrm{s}($ SEM $500 \mathrm{x}$ mag.)

The failure mechanisms were similar in the wires for all but the lowest fragment velocity $\left(V_{i}=297 \mathrm{~m} / \mathrm{s}\right)$.

SEM inspections were carried out on wires from each and are shown Figs. 14 to 18. 


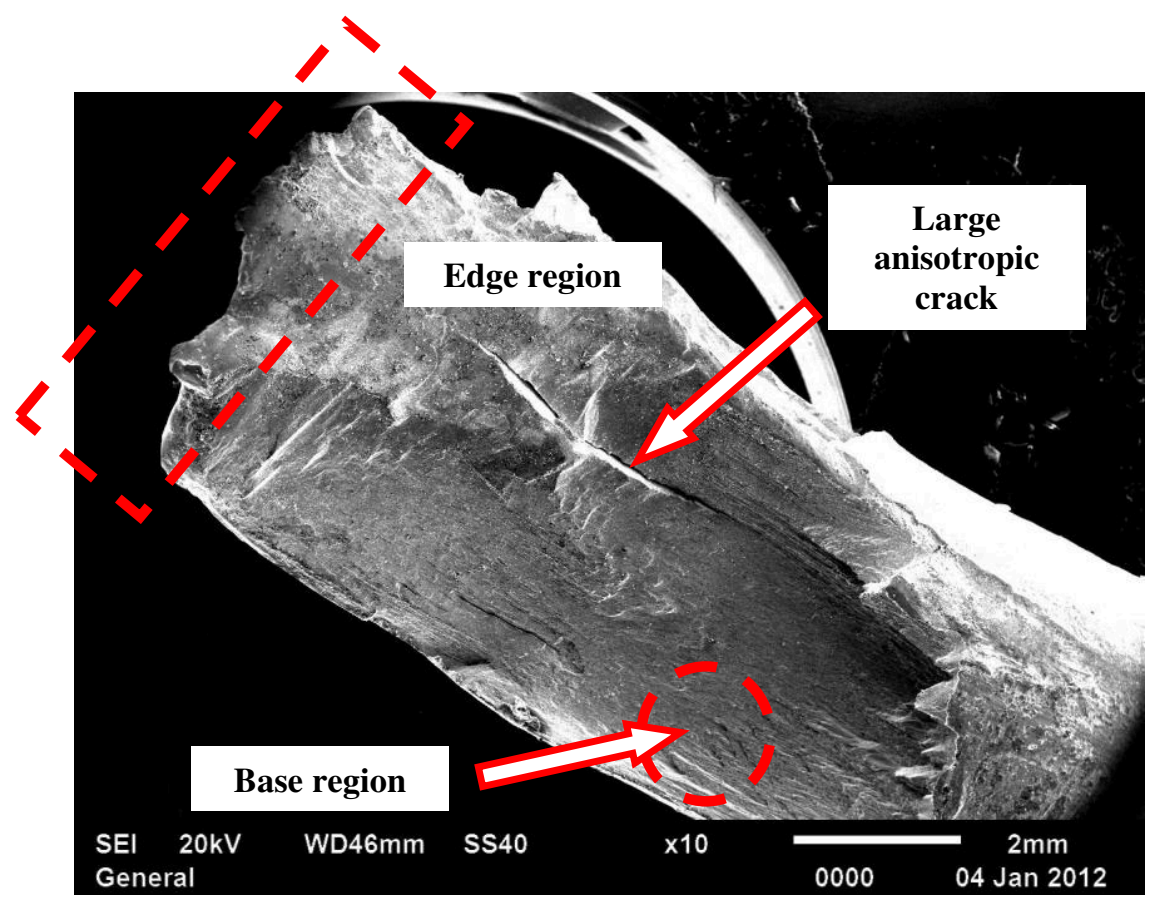

(a) Overall damage: $V_{i}=680 \mathrm{~m} / \mathrm{s}$ (SEM $10 \mathrm{x}$ mag.)

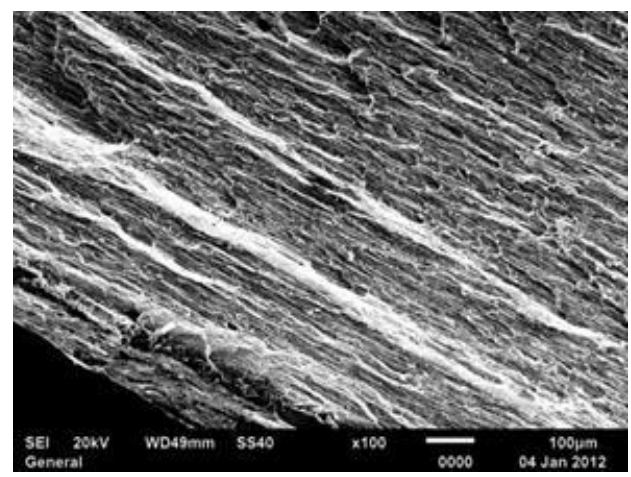

(b) Base region: $V_{i}=680 \mathrm{~m} / \mathrm{s}$ (SEM $100 \mathrm{x}$ mag.)

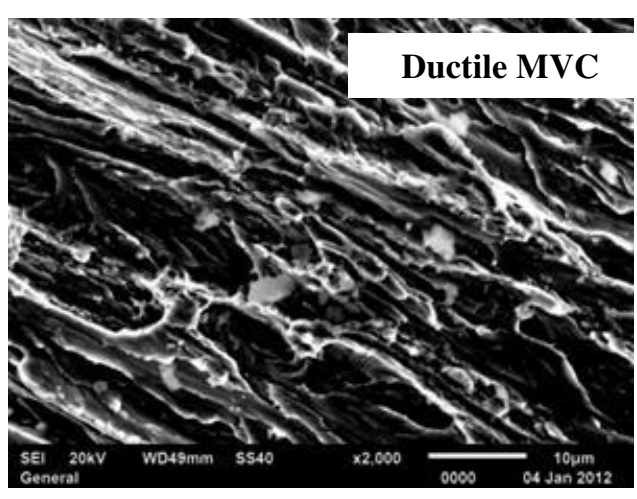

(d) Base region: $V_{i}=680 \mathrm{~m} / \mathrm{s}$

(SEM $2000 \mathrm{x}$ mag.)

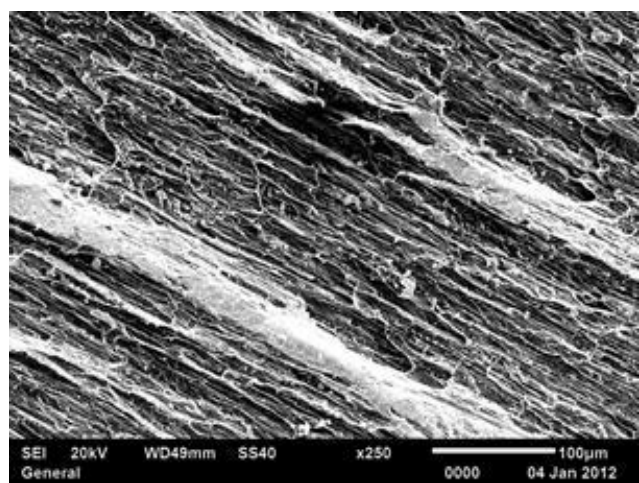

(c) Base region: $V_{i}=680 \mathrm{~m} / \mathrm{s}$ (SEM $100 \mathrm{x}$ mag.)

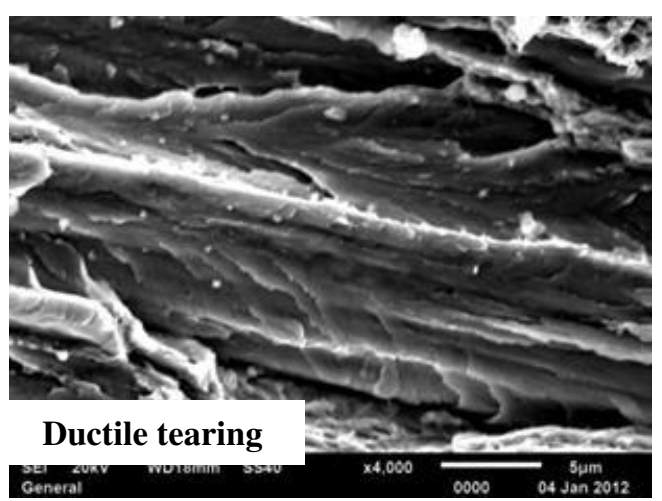

(e) Base region: $V_{i}=680 \mathrm{~m} / \mathrm{s}$ (SEM $4000 \mathrm{x}$ mag.) 
Fig. 14 SEM inspection of base region of fractured wire for $V_{i}=680 \mathrm{~m} / \mathrm{s}$

Fig. 14a shows a similar surface to that shown in Fig. 11(a) with the exception of what appears to be a large anisotropic crack. This may have been caused by a pre-occupant irregularity or a result of the anisotropic nature of the microstructure resulting in a weakness in the transverse direction across the wire. Figs. 14b-e display the ductile tearing across the service resulting from MVC. Fig. 15 shows the edge region clearly indicating the smearing lines from the fragment impact.

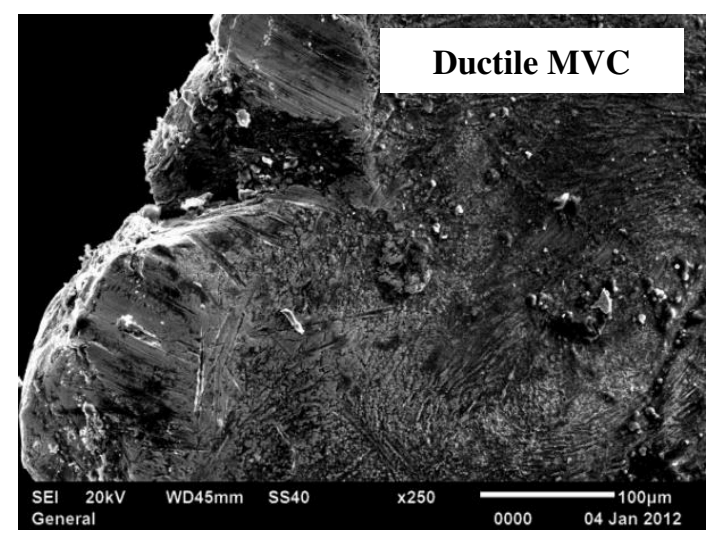

(a) Edge region: $V_{i}=680 \mathrm{~m} / \mathrm{s}$ (SEM 250 x mag.)

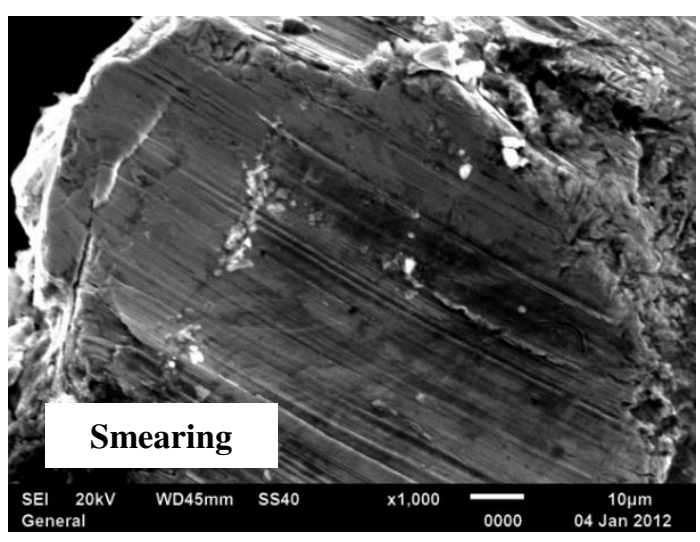

(b) Edge region: $V_{i}=680 \mathrm{~m} / \mathrm{s}$ (SEM $1000 \times$ mag.)

Fig. 15 SEM inpsection of edge region of fractured wire for $V_{i}=680 \mathrm{~m} / \mathrm{s}$

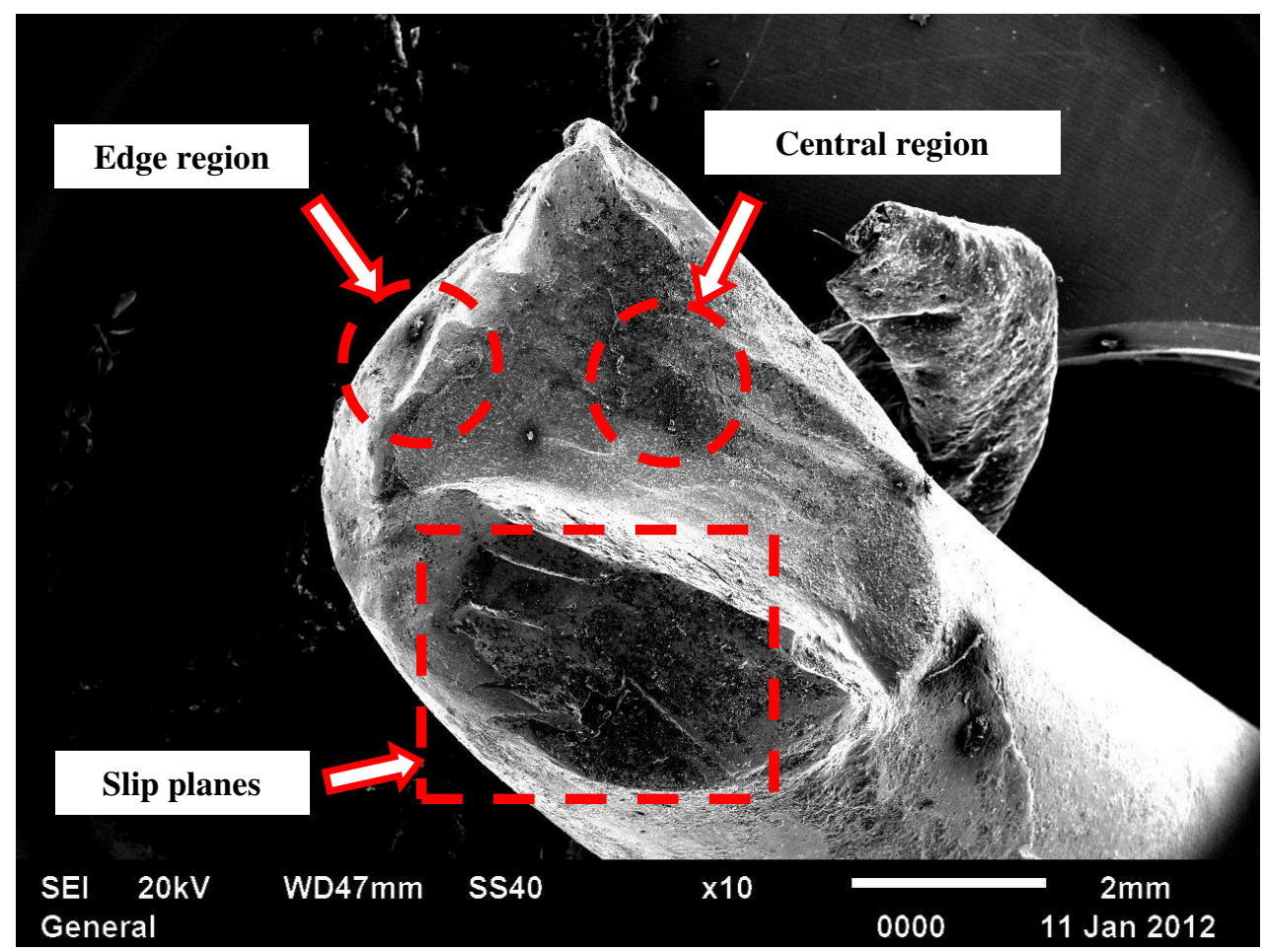


(a) Overall damage: $V_{i}=580 \mathrm{~m} / \mathrm{s}$ (SEM $10 \mathrm{x}$ mag.)

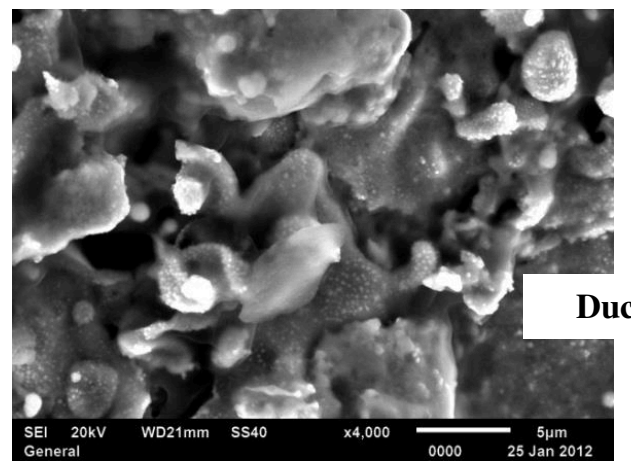

(b) Central region: $V_{i}=580 \mathrm{~m} / \mathrm{s}$

(SEM $4000 \mathrm{x}$ mag.)

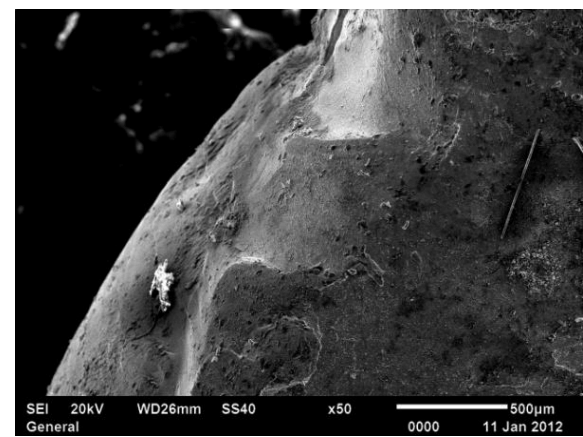

(d) Edge region: $V_{i}=580 \mathrm{~m} / \mathrm{s}$

(SEM 50 x mag.)

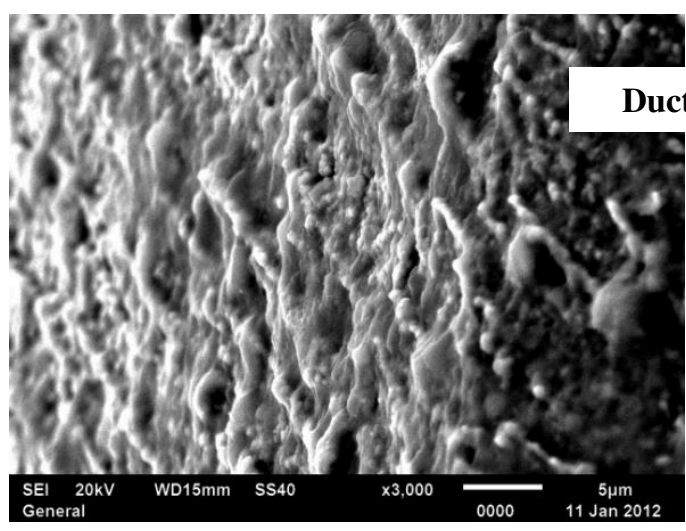

(f) Edge region: $V_{i}=580 \mathrm{~m} / \mathrm{s}$

(SEM $3000 \mathrm{x}$ mag.)

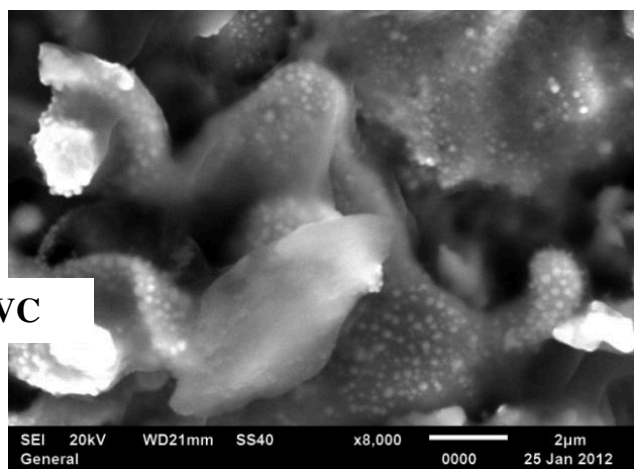

(c) Central region: $V_{i}=580 \mathrm{~m} / \mathrm{s}$

(SEM 8000 x mag.)

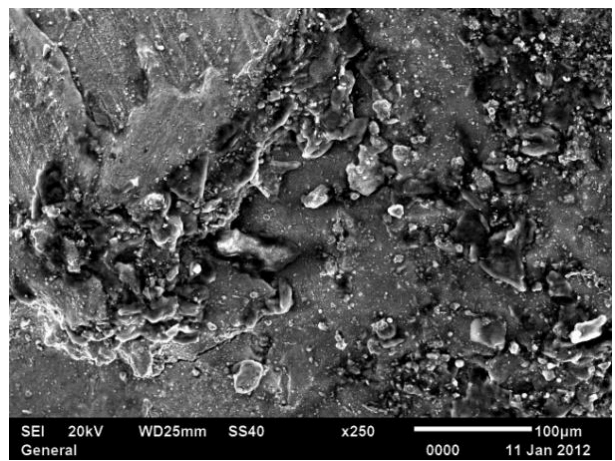

(e) Edge region: $V_{i}=580 \mathrm{~m} / \mathrm{s}$

(SEM $250 \times$ mag.)

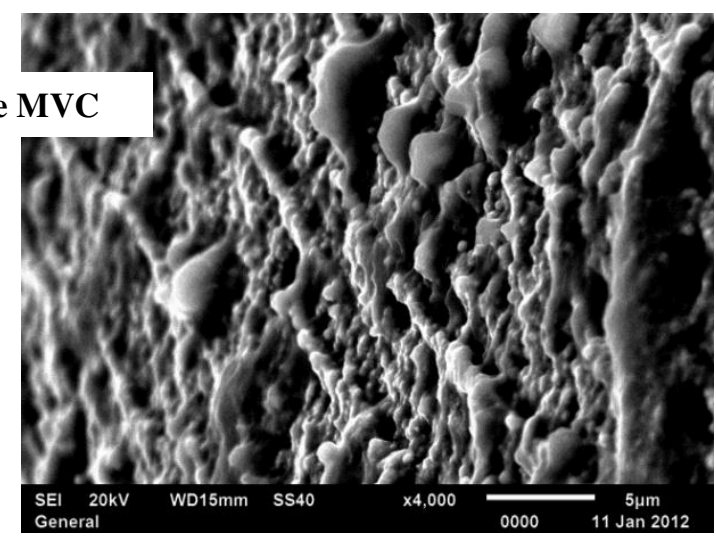

(g) Edge region: $V_{i}=580 \mathrm{~m} / \mathrm{s}$

(SEM $4000 \times$ mag.)

Fig. 16 SEM inpsection of edge region of fractured wire for $V_{i}=580 \mathrm{~m} / \mathrm{s}$ 


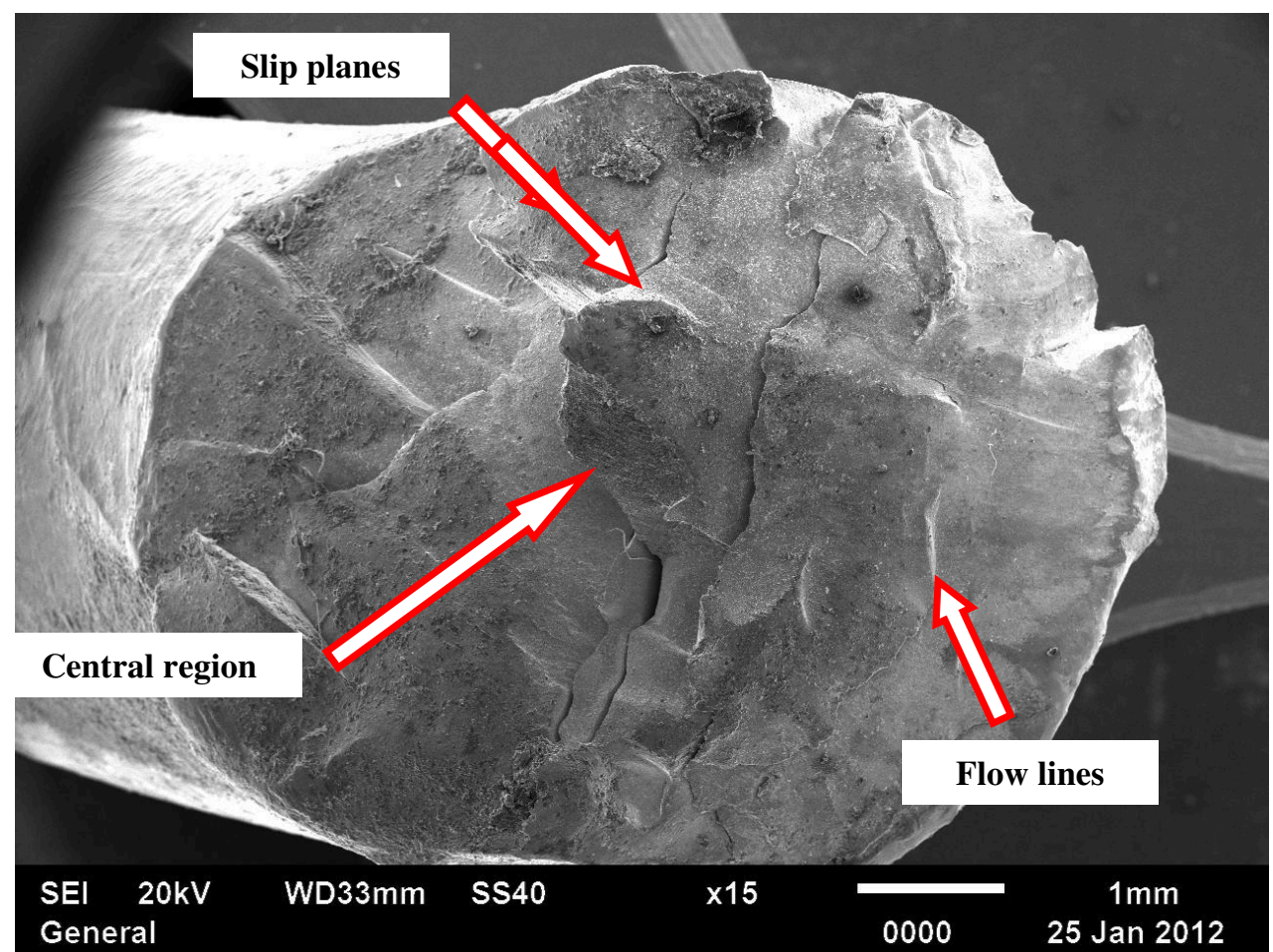

(a) Overall damage: $V_{i}=501 \mathrm{~m} / \mathrm{s}$ (SEM $15 \mathrm{x}$ mag.)

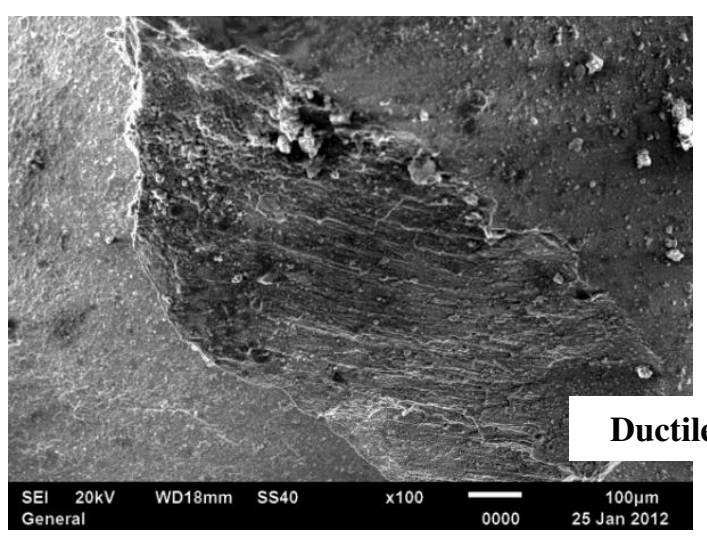

(b) Central region: $V_{i}=501 \mathrm{~m} / \mathrm{s}$ (SEM $100 \mathrm{x}$ mag.)

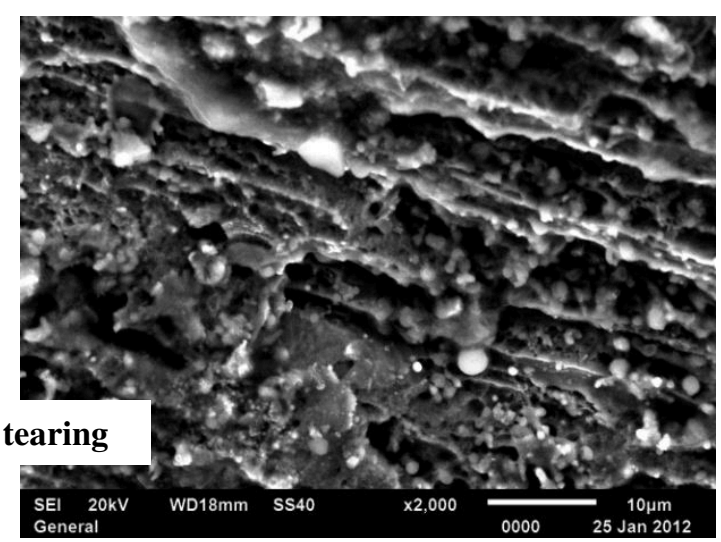

(c) Central region: $V_{i}=501 \mathrm{~m} / \mathrm{s}$ (SEM $500 \mathrm{x}$ mag.)

Fig. 17 SEM inpsection of fractured wire for $V_{i}=501 \mathrm{~m} / \mathrm{s}$ 


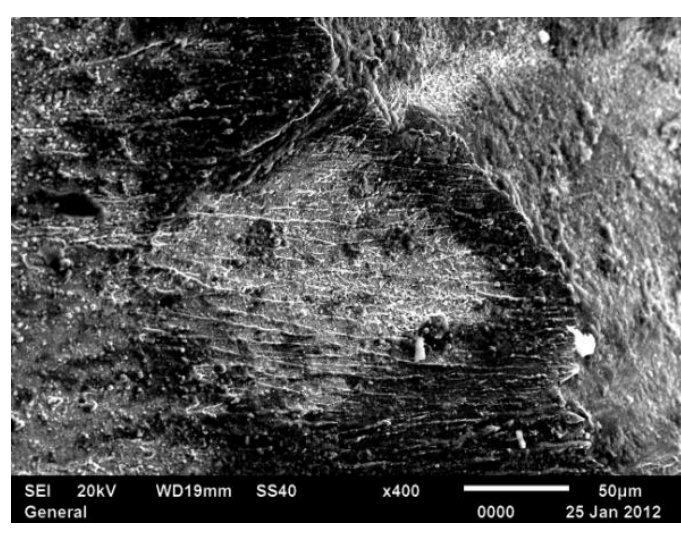

(a) Edge region: $V_{i}=501 \mathrm{~m} / \mathrm{s}$

(SEM $400 \mathrm{x}$ mag.)

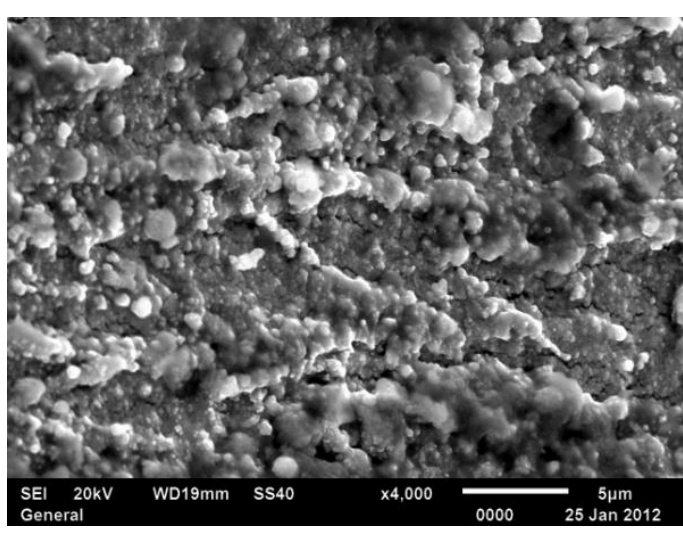

(c) Edge region: $V_{i}=501 \mathrm{~m} / \mathrm{s}$

(SEM 4000 x mag.)

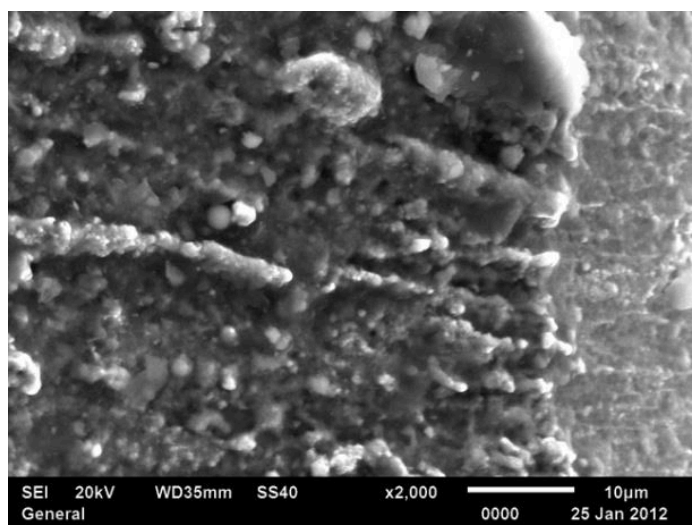

(b) Edge region: $V_{i}=501 \mathrm{~m} / \mathrm{s}$ (SEM 2000 x mag.)

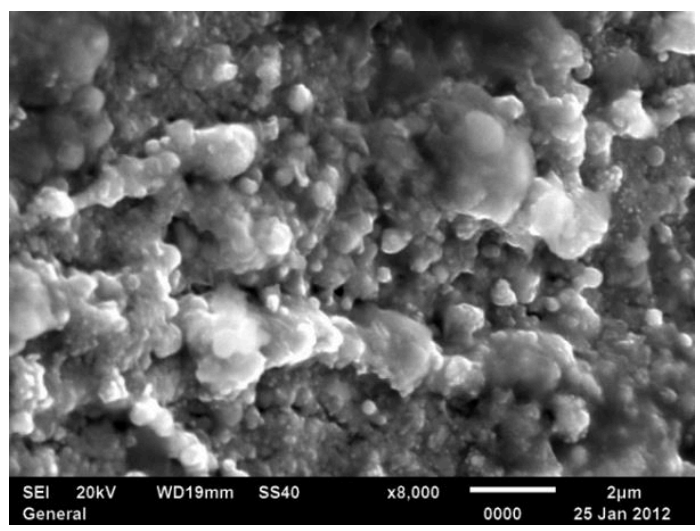

(d) Edge region: $V_{i}=501 \mathrm{~m} / \mathrm{s}$ (SEM $8000 \times$ mag.)

Fig. 18 SEM inpsection of edge region of fractured wire for $V_{i}=501 \mathrm{~m} / \mathrm{s}$

This brief metallurgical assessment of the fractured wires has enabled the individual wire failure mechanism to be visualised and understood at the microscale. The failure mechanism is a complex one which is transitional and ductile in nature. At the point of impact an intense compression is induced in a zone between the fragment and wires deeper into the cable leading to the wire material at the impact interface being transversely smeared creating shearing planes and tearing effects resulting in MVC. The benefit of carrying out an assessment such as this is that the results can be used to inform the type of constitutive material modelling to be adopted in the numerical simulations. This is discussed further in Section 4.

\subsection{Fragment simulating project deformation}

Fig. 19 shows the deformed FSPs after impact for $V_{i}=297 \mathrm{~m} / \mathrm{s}, 680 \mathrm{~m} / \mathrm{s}$ and $1328 \mathrm{~m} / \mathrm{s}$. As expected, the plastic deformation and damage sustained by the FSP was so significant for $V_{i}=1328 \mathrm{~m} / \mathrm{s}$ that its original shape became beyond recognition, while the impact at lower velocities led to mushroom-shaped fragments with clear indentations from the wires. 

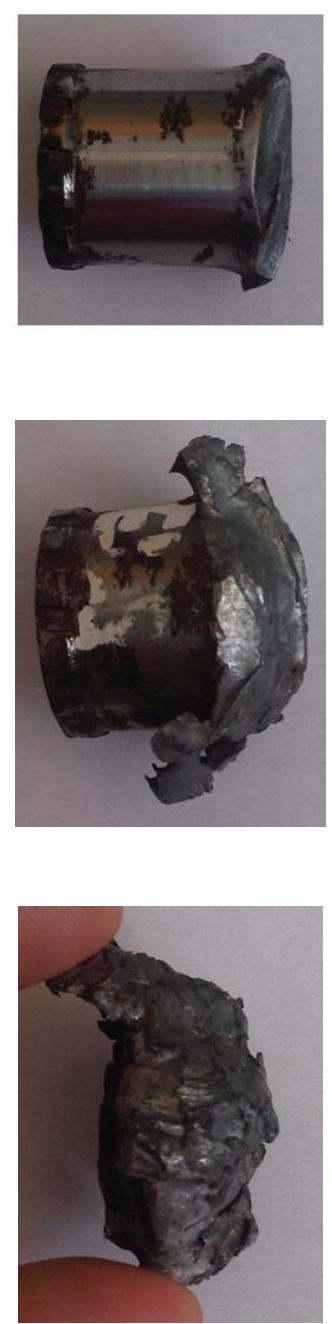
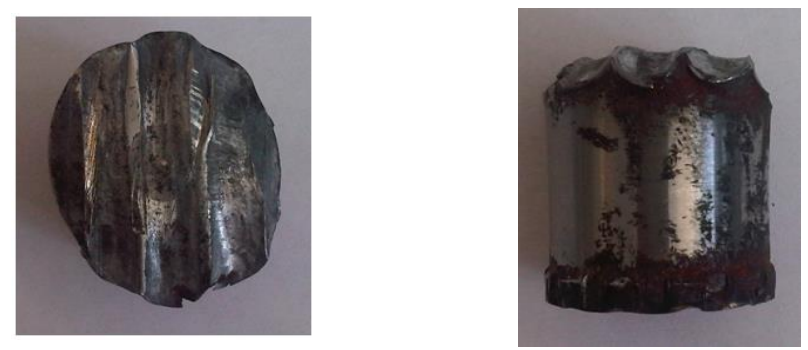

(a) $V_{i}=297 \mathrm{~m} / \mathrm{s}$
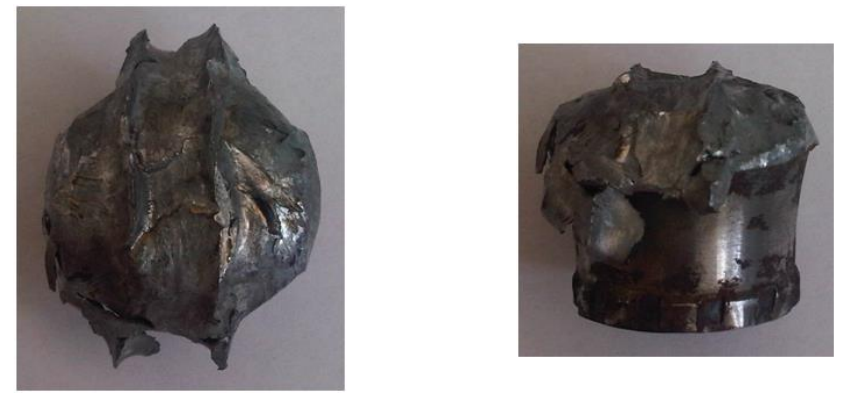

(b) $V_{i}=680 \mathrm{~m} / \mathrm{s}$
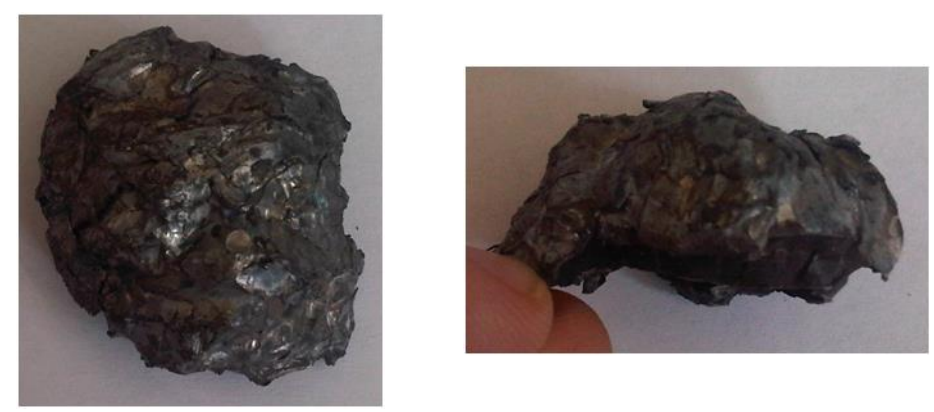

(c) $V_{i}=1328 \mathrm{~m} / \mathrm{s}$

Fig. 19 Deformed fragments post impact

\section{Numerical Simulations}

This section focuses on the development of numerical models using LS-DYNA with careful comparison to the experimental test results.

\subsection{Material Modelling}

A complete material description under impact involves the stress as a function of strain, strain rate, temperature, accumulation of damage and failure $[14,15]$. The modified Johnson-Cook constitutive model [16] was used to simulate the materials of both the cables and fragments. The model is widely denoted as the MJC model to distinguish it from the original one [17]. It has proven to give accurate results in previous studies on the perforation resistance of high strength steel plates (e.g. Refs. [18-20]). Further studies on its 
applicability and validity are also reported in [21-23]. In the model the equivalent stress is expressed by Equation 4.1.

$\sigma_{e q}=\left[A+B \varepsilon_{e q}{ }^{n}\right]\left[1+\dot{\varepsilon}_{e q}{ }^{*}\right]^{\mathrm{C}}\left[1-T^{* m}\right]$

where $A$ is the yield strength, $B$ the hardening modulus, $\varepsilon_{e q}$ the equivalent plastic strain, $C$ the strain rate sensitivity coefficient, $n$ the hardening coefficient, $m$ the thermal softening coefficient, and $\dot{\varepsilon}_{e q}{ }^{*}$ a dimensionless plastic strain rate given by $\dot{\varepsilon}_{e q} / \dot{\varepsilon}_{0}$, where $\dot{\varepsilon}_{0}$ is a user-defined reference strain rate. In Equation (4.1), the terms in the three brackets represent the strain hardening, the strain-rate sensitivity and the temperature softening, respectively.

The homologous temperature is defined by Equation 4.2.

$T^{*}=\left(T-T_{r}\right) /\left(T_{m}-T_{r}\right)$

where $T$ is the absolute temperature and $T_{r}$ is the room temperature. The temperature increase due to adiabatic heating is calculated using Equation 4.3.

$$
\Delta T=\int_{0}^{\varepsilon_{e q}} \chi \frac{\sigma_{e q} d \varepsilon_{e q}}{\rho C_{P}}
$$

where $\rho$ is the material density, $C_{p}$ the specific heat and $\chi$ the Tayor-Quinney coefficient that represents the proportion of plastic work converted into heat.

An alternative option to the JC and MJC constitutive model would be the Zerilli and Armstrong constitutive relation. However, The MJC relationship has been used for all fragment impact simulations in the present study due to its simplicity and less involved calibration process.

\subsection{Fracture criteria}

Material failure in both the cable and fragment was modelled using the Cockcroft-Latham (CL) fracture criterion [24] as defined in Equation 4.2.

$$
W=\int_{0}^{\varepsilon_{e q}}\left\langle\sigma_{1}\right\rangle d \varepsilon_{e q} \leq W_{c r}
$$

The model is expressed as the plastic work $\mathrm{W}$ per unit volume where $\sigma 1$ is the major principal stress, \langle\rangle$=$ 
$\sigma 1$ when $\sigma 1 \geq 0$ and \langle\rangle$=0$ when $\sigma 1<0$ [23]. The critical value of the plastic work per unit volume (Wcr) can be determined from one simple uniaxial tensile test. Moreover, the model is able to capture observed material behaviour for most steels exposed to impact and it was shown in [21-23] that the single parameter (Wcr) Cockcroft-Latham fracture criterion gives equally good results as the five parameters (D1 to D5) in the Johnson-Cook fracture criterion in LS-DYNA simulations of perforation of steel plates. Further discussions regarding the use of the fracture criterion in high velocity projectile simulations can be found in [25-27]. The MJC constitutive relation and CL fracture criterion have been implemented in LS-DYNA as MAT_107: MODIFIED_JOHNSON_COOK [7] and are readily available for use coupled or uncoupled. The models are coupled with an element kill algorithm that removes damaged elements from the mesh when the damage variable reaches $W_{c r}$. In addition, a temperature based erosion criteria can also be initiated based on the critical temperature which is taken as $T_{c}=0.9 T_{m}$. This means that when the temperature in the material reaches $90 \%$ of the melting temperature, the element is eroded. It is assumed at these temperatures, the material is so weak that it does not offer much impact resistance.

\subsection{Material parameters for wires}

A limited identification procedure has been applied to determine the parameters for the MJC and CL models for the wires and fragment materials. For the wires, the yield stress A, the hardening parameters B and $\mathrm{n}$, and the critical plastic work Wcr were determined by least square fitting of the Brigman corrected true stress-strain curve derived in [8] for $1770 \mathrm{MPa}$ (UTS) wire used in spiral, locked coil and wire rope strand. Due to the lack of strain-rate sensitivity data available in the open literature for high strength structural cable wire, the wires were assumed to be insensitive to strain rate. It is highlighted in [16] that with increasing static stress, material sensitivity to strain rate is significantly reduced according to [28]. This was observed physically in [23] in high strength steel alloys subjected to high strain rate tensile tests. It is unknown whether significant strain-rate sensitivity would be observed in the high strength steel wires being considered in the present study and further research is ongoing to confirm this with Bridon International Ltd. On that basis, the strain rate sensitivity parameter $\mathrm{C}$ was assigned a very small positive value based on findings in [29]. The thermal softening parameter $\mathrm{m}$ was taken as 1.0 , which assumes a linear reduction in strength with increase in temperature which seems a reasonable assumption for steel. Again, as with the strain rate parameter, further testing on the wires at elevated temperatures is required to confirm this. The material parameters used in the simulations for wires of the strand are outlined in Table 4.

Table 4 Material parameters for the MJC constitutive relation and CL fracture criterion used for the wires the make up the $60 \mathrm{~mm}$ diameter spiral strand

\begin{tabular}{cccc}
\hline $\begin{array}{c}\text { Elastic constants } \\
\text { and density }\end{array}$ & $\begin{array}{c}\text { Yield stress and } \\
\text { strain-hardening }\end{array}$ & $\begin{array}{c}\text { Strain rate } \\
\text { hardening }\end{array}$ & $\begin{array}{c}\text { Cockcroft-Latham } \\
\text { Failure }\end{array}$ \\
\hline
\end{tabular}




\begin{tabular}{ccc}
\hline$E=200(\mathrm{GPa})$ & $A=1980(\mathrm{MPa})$ & $\dot{\varepsilon}_{0}=5 \times 10^{-4}\left(\mathrm{~s}^{-1}\right)$ \\
$v=0.33(\mathrm{MPa})$ & $B=375(\mathrm{MPa})$ & $W_{c r}=1350(\mathrm{MPa})$ \\
$\rho=7850 \mathrm{~kg} / \mathrm{m}^{3}$ & $\mathrm{n}=0.81$ & \\
\hline \multicolumn{3}{c}{ Adiabatic heating and temperature softening } \\
\hline$C_{p}=452(\mathrm{~J} / \mathrm{kgK})$ & $T_{r}=293(\mathrm{~K})$ & $T_{c}^{*}=1620(\mathrm{~K})$ \\
$\chi=0.9$ & $T_{m}=1800(\mathrm{~K})$ & \\
$\alpha=1.1 \times 10^{-5}$ & $m=1.0$ & \\
\hline
\end{tabular}

\subsection{Material parameters for fragment simulating projectile (FSP)}

The FSP is manufactured from cold rolled annealed steel conforming to $4337 \mathrm{H}$ and $4340 \mathrm{H}$ or equivalent and has a hardness value HRC $30 \pm 2$. The material parameters used in the simulations have been taken directly from [17]. The material parameters are highlighted in Table 5.

Table 5 Constants in the MJC and CL models used for FSP

\begin{tabular}{ccccc}
\hline Strain Hardening & $\begin{array}{c}\text { Strain rate } \\
\text { Hardening }\end{array}$ & $\begin{array}{c}\text { Temperature } \\
\text { Softening }\end{array}$ & CL Failure & $\begin{array}{c}\text { Temperature } \\
\text { cut-off }\end{array}$ \\
\hline$A=792(\mathrm{MPa})$ & $\dot{\varepsilon}_{0}=5 \times 10^{-4}\left(\mathrm{~s}^{-1}\right)$ & $T_{r}=293(\mathrm{~K})$, & & \\
$B=510(\mathrm{MPa})$ & $C=0.014$ & $T_{m}=1775(\mathrm{~K})$, & $W_{c r}=1350(\mathrm{MPa})$ & $T_{c}^{*}=1598(\mathrm{~K})$ \\
$n=0.26$ & & $m=1.0$ & &
\end{tabular}

Other material parameters used in the simulations for both the cable and FSP are listed in Table 6.

Table 6 Common material properties

\begin{tabular}{llll}
\hline$E=210,000(\mathrm{MPa})$ & $v=0.3, \quad \rho=7850 \mathrm{~kg} / \mathrm{m}^{3}$ & $C_{p}=452 \mathrm{~J} / \mathrm{kgK}$, & $\chi=0.9$
\end{tabular}

As highlighted in [23] only moderate pressures are generated for solid-solid impacts in the $0.5-2 \mathrm{~km} / \mathrm{s}$ velocity regime [14, 15 and 30]. The Mie-Grunesian equation-of-state [7] was used in the simulations and the parameters considered for steel are highlighted in Table 7.

Table 7 Mie-Grunesian equation-of-state parameters

\begin{tabular}{lll}
\hline$C_{0}=6100 \mathrm{~m} / \mathrm{s}$ & $S=1.49$ & $\Gamma_{0}=1.93$
\end{tabular}


where $C_{0}$ is the bulk wave velocity, $S=$ shockwave velocity parameter and $\Gamma_{0}$ is the Grunesian coefficient for steel [31-33].

\subsection{Finite Element Model}

An effective procedure to generate 3D finite element models for complicated spiral strands has been devised in [34] for quasi-static analysis and has been used to generate the cable models in the present study. The element sizes in the cable cross-section varied with the diameter of the individual wires. Twenty elements were used on the circumference direction of each wire to achieve a sensible radial contact between the wires, resulting in a total of 105 elements across each wire cross-section. The largest and smallest element sizes in the largest and smallest diameter wires, were approximately $1.25 \mathrm{~mm} \times 1.25 \mathrm{~mm}$ and $0.25 \mathrm{~mm} \times 0.25 \mathrm{~mm}$, respectively. The FSP model was developed using the geometry outlined in [6]. The maximum and minimum element sizes that make up the FSP were $1.6 \mathrm{~mm} \times 1.6 \mathrm{~mm}$ and $1.4 \mathrm{~mm} \times 1.4$ $\mathrm{mm}$ respectively. Increased density meshing at the impact zone was difficult to achieve without numerical instabilities occurring due to the spiralling geometry of each wire. Therefore, the mesh density was governed by that at the impact zone and was kept uniform across the cable length considered, i.e. no coarsening at the boundaries of the cable model. The overall model (cable and fragment) was constructed with fully integrated solid elements and appropriate hourglass control [35].

The cable-end boundary conditions allowed only axial translation of the wires at both ends in the longitudinal z-direction based on the observations presented in Fig. 7 (i.e. longitudinal wire drag). All other degrees of freedom were fixed. These boundary conditions were applied to $300 \mathrm{~mm}$ long length segment lengths at each end.

Contact between 1) adjacent wires, and between 2) the wires and fragment were modelled using the *ERODING_SURFACE_TO_SURFACE penalty formation available in LS-DYNA [7]. This algorithm can not only model the wire-to-wire contact, but re-calculates contact surfaces when failed elements are removed from the mesh i.e. the contact surface is never lost. A dynamic coefficient of 0.1 has been proposed by [36]. Others have suggested a lower value of 0.05 be used for the lateral surfaces in impact situations due to the high velocities and temperatures. In a recent study [37] the effects of friction was numerically studied for a seven wire strand following the method of strand construction developed in [34]. In the study, longitudinal stretching and lateral loading conditions were considered to determine the influence of friction on the response of the strand under each loading condition. The study concluded that the friction coefficient range considered $(0.115,0.2$ and 0.4$)$ had minimal influence on the longitudinal (axial load) response of the strand. In the lateral loading analysis, the results showed that friction influenced lateral stiffness more than longitudinal stiffness but the effect was still limited. The friction coefficient used was kept at 0.115 in accordance with [38 and 39]. 
The full finite element model consisting of both the cable and fragment is shown in Fig. 20. The mesh has 10,087,568 8-noded solid elements and 11,158,545 nodes. The LS-DYNA/Explicit module was used and a simulation took about 12-15 hours on a high performance LINUX cluster using INTEL E5-2690v2 CPU's using 16 cores.

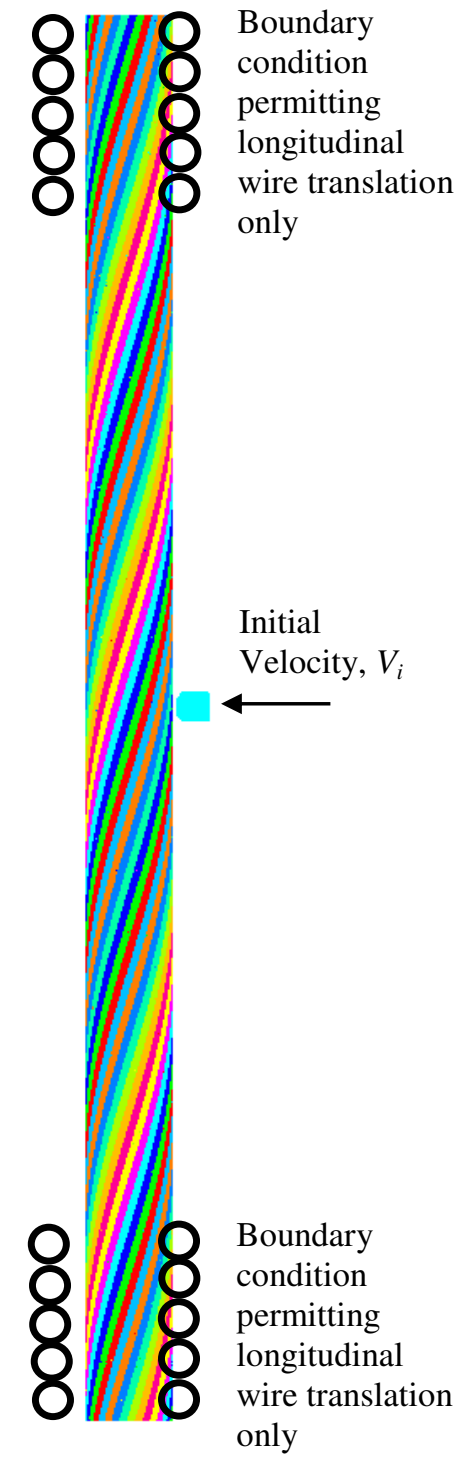

(a) Overall impact model
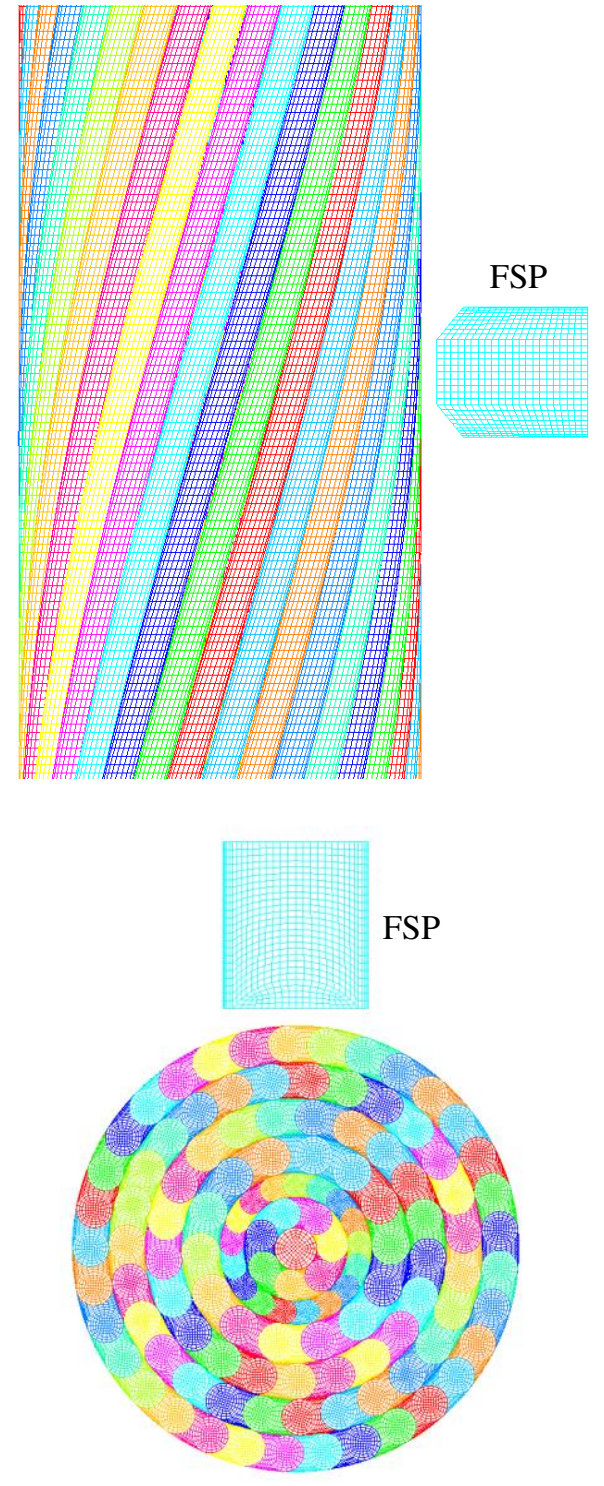

(b) Localised images of model meshing

Fig. 20 Complete finite element model with cable and fragment

\subsection{Results and discussion}

\subsubsection{Zero-obliquity impact simulations}


Fig. 21 shows the cables with damage obtained from numerical simulations of zero-obliquity FSP impact. The fringes represent regions of high plastic strain. Generally, the modelling reproduced many of the key characteristics of the cable impact tests. In all simulations, the fragments penetrate and rebound from the cables as was observed in the testing and the fragment penetration depth was similar in all cases. The fragment penetration depth was is measured in the testing and numerical simulations from the front (impacted) face of the cable to maximum depth to indented wires in the core of the cable.

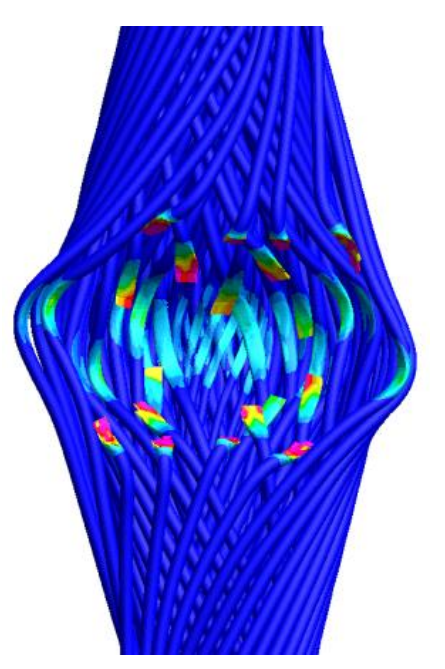

(a) $1328 \mathrm{~m} / \mathrm{s}$

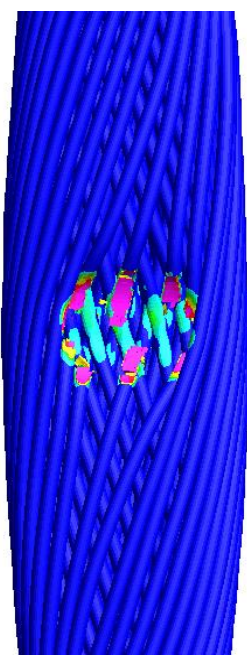

(d) $501 \mathrm{~m} / \mathrm{s}$

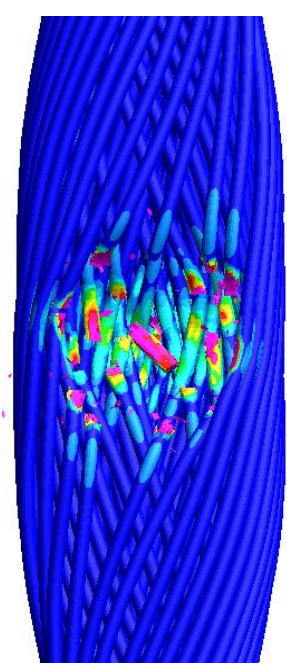

(b) $680 \mathrm{~m} / \mathrm{s}$

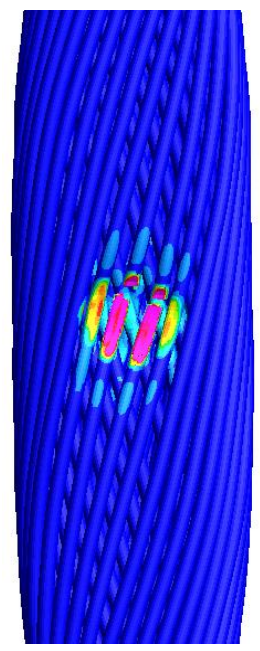

(e) $360 \mathrm{~m} / \mathrm{s}$

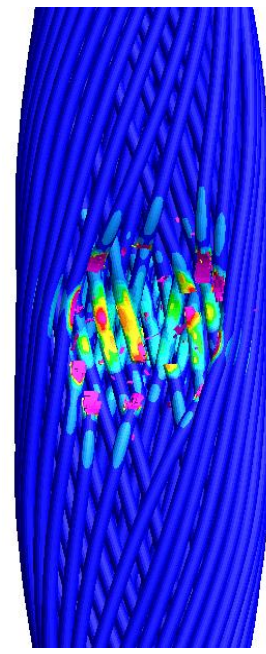

(c) $580 \mathrm{~m} / \mathrm{s}$

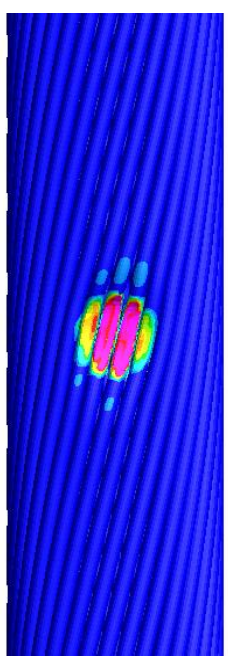

(f) $297 \mathrm{~m} / \mathrm{s}$

Fig. 21 Predicted cable damage from zero-obliquity FSP impact simulations 1-6

As is seen from Fig. 21, the plasticity and resulting damage was localised at the impact zone. In allowing longitudinal wire translation at the ends of each of the cable models, the horizontal wire splaying could be captured as was observed in the tests at the highest impact velocities. In a fully tensioned cable this would 
be less pronounced given the distance to the cable end-boundary coupled with the tension force acting in the cable. Figs. 22 to 24 show numerical simulation stills for the highest, mid and lowest impact velocities. As observed in the testing, the wires were flattened against those below resulting in a ductile thinning-tofailure mechanism as discussed in Section 3.
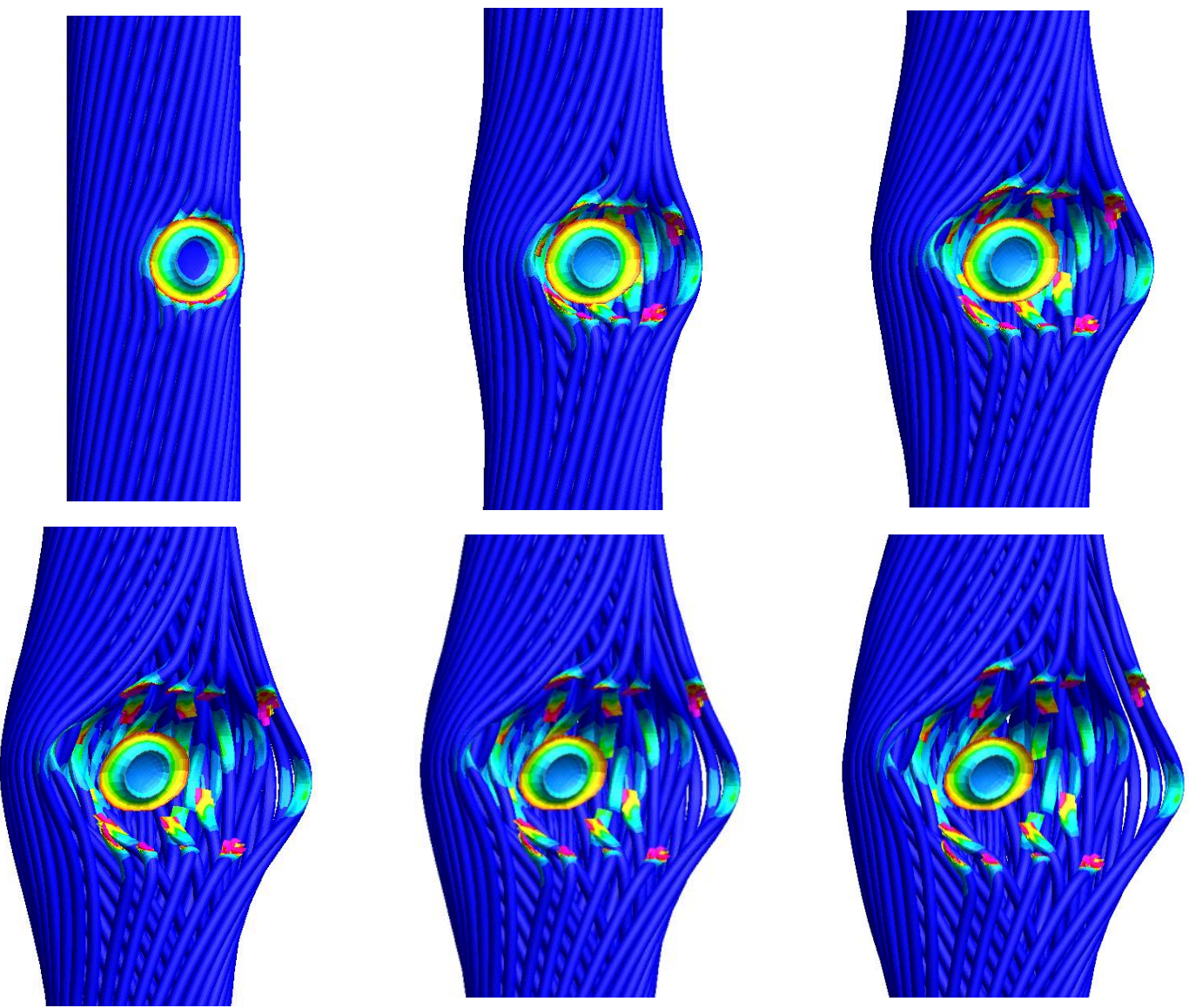

Fig. 22 Numerical simulation 1 stills at $V_{i}=1328 \mathrm{~m} / \mathrm{s}$ 

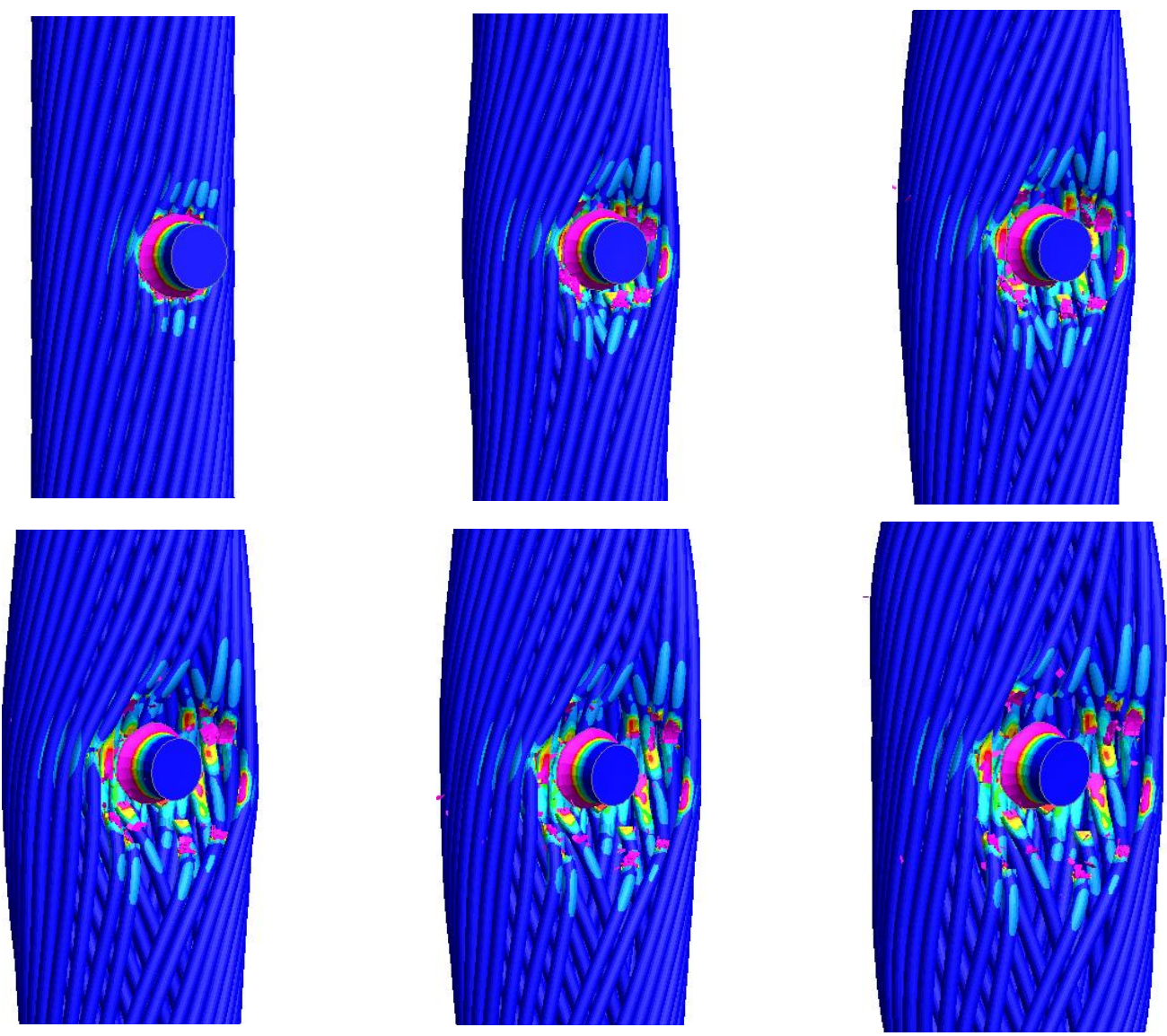

Fig. 23 Numerical simulation 2 stills at $V_{i}=680 \mathrm{~m} / \mathrm{s}$ 

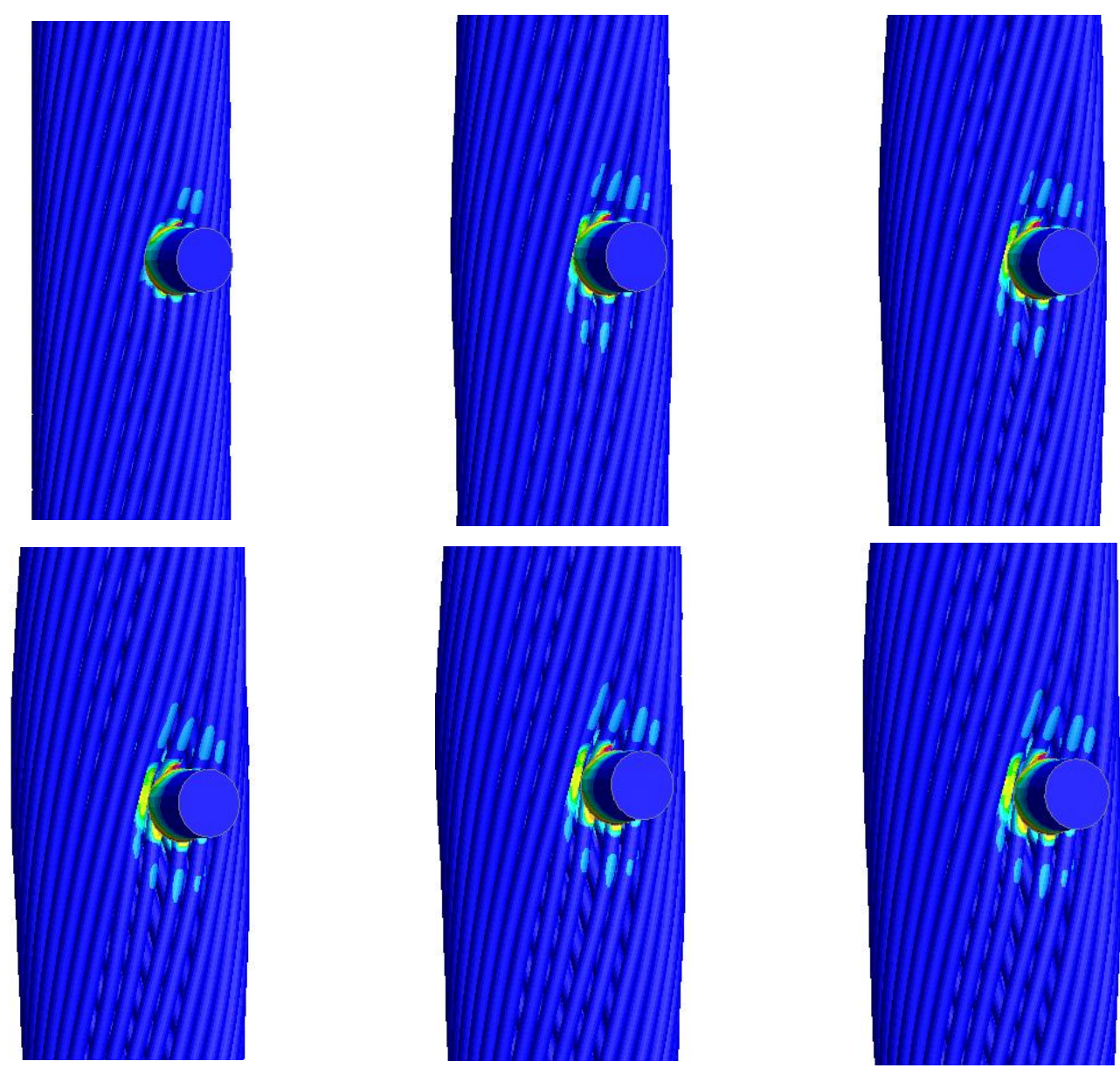

Fig. 24 Numerical simulation 6 stills at $V_{i}=297 \mathrm{~m} / \mathrm{s}$

Fig. 25 shows some comparative images of failed wires from the $V_{i}=1328 \mathrm{~m} / \mathrm{s}, V_{i}=680 \mathrm{~m} / \mathrm{s}$ and $V_{i}=501$ $\mathrm{m} / \mathrm{s}$ numerical simulation. As is seen, individual wire failure was represented well by the simulations demonstrating the applicability of the MJC constitutive relation and CL fracture criterion for the present study. 


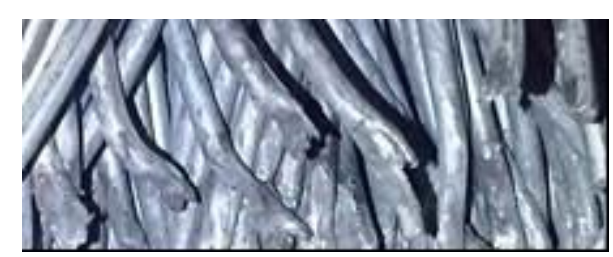

(a)

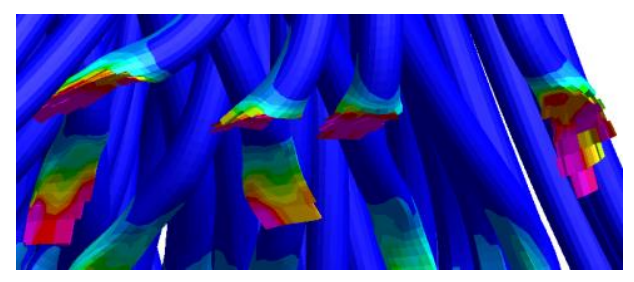

(c)

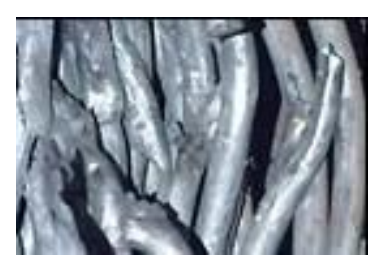

(b)

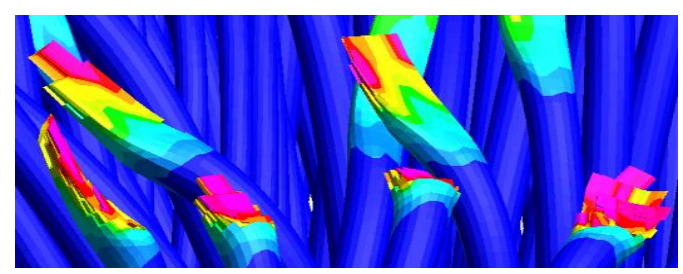

(d)

(numerical and experimental physical comparisons) for $V_{i}=1328 \mathrm{~m} / \mathrm{s}$

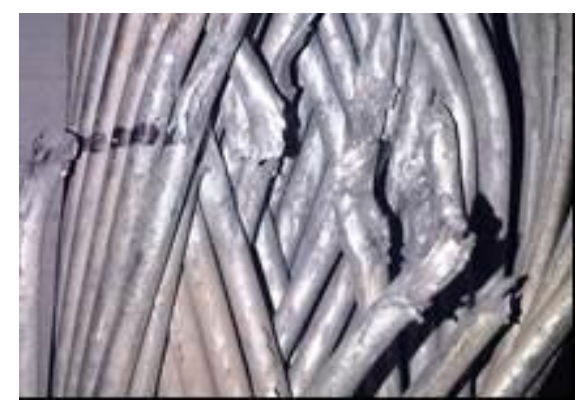

(e)

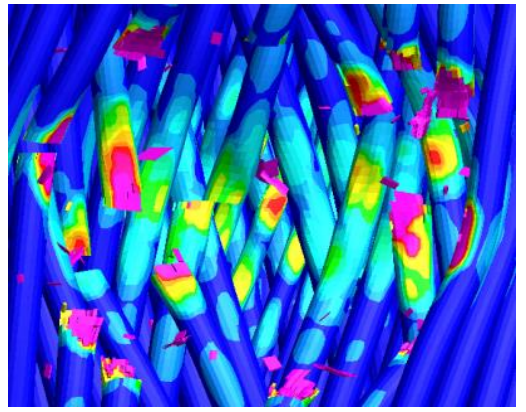

(f)

(numerical and experimental physical comparisons) for $V_{i}=680 \mathrm{~m} / \mathrm{s}$

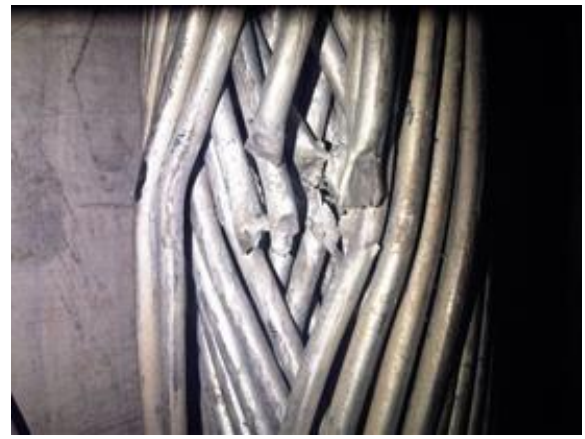

(g)

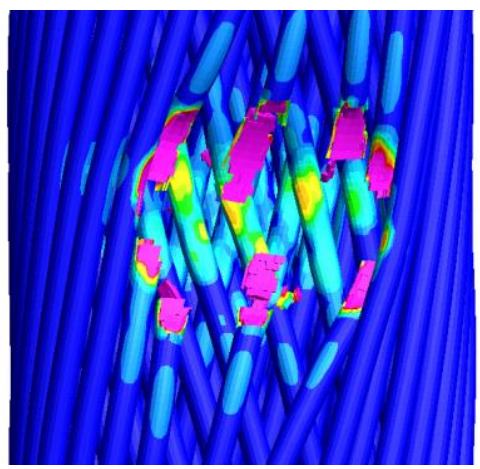

(h)

(numerical and experimental physical comparisons) for $V_{i}=501 \mathrm{~m} / \mathrm{s}$

Fig. 25 individual wire failure mechanism 
One of the key advantages of high velocity impact simulations is the ability to observe phenomena that are difficult, if not impossible, to record in an experimental test. Fig. 26 shows the maximum levels of effective plastic strain developed at the centre of the impact zone as a function of time for simulations 1-6 as depicted by the contours in earlier figures.

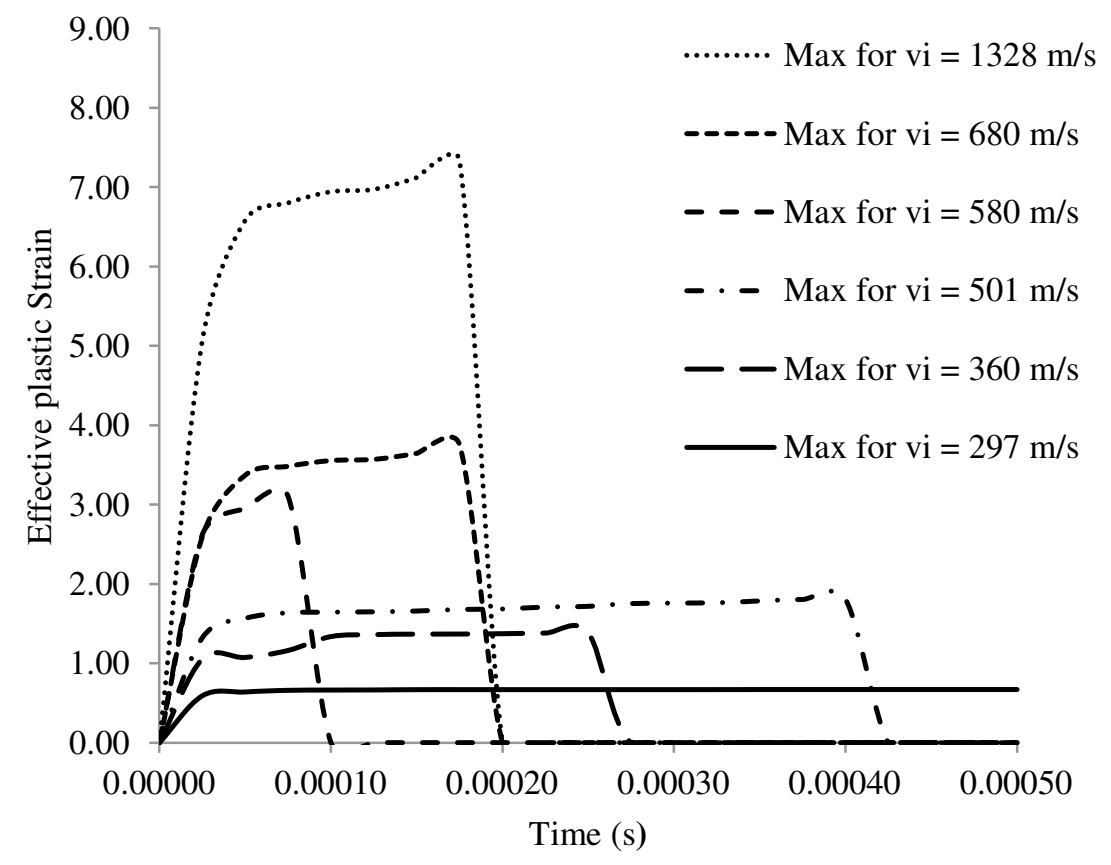

Fig. 26 Effective plastic strains developed for simulations 1-6

Plastic straining of the material increases rapidly at the point of impact. Fig. 26 shows the maximum effective plastic strain developed in the wires on impact for each FSP impact velocity. The sudden drop in effective plastic strain is due to element erosion. This occurred in simulations $1-5$. No element erosion was observed in simulation No. $6(\mathrm{Vi}=297 \mathrm{~m} / \mathrm{s})$ which corresponds well with the test in which the fragment induced some minor indentation at the impact zone and then rebounded from the surface. The plot shows that at $\mathrm{Vi}=1328 \mathrm{~m} / \mathrm{s}$ the maximum effective plastic strain is observed (about 7.3) at a corresponding strain rate of $450001 / \mathrm{s}$

Fig. 27 shows the strain rates developed on impact for all zero-obliquity FSP impacts. 


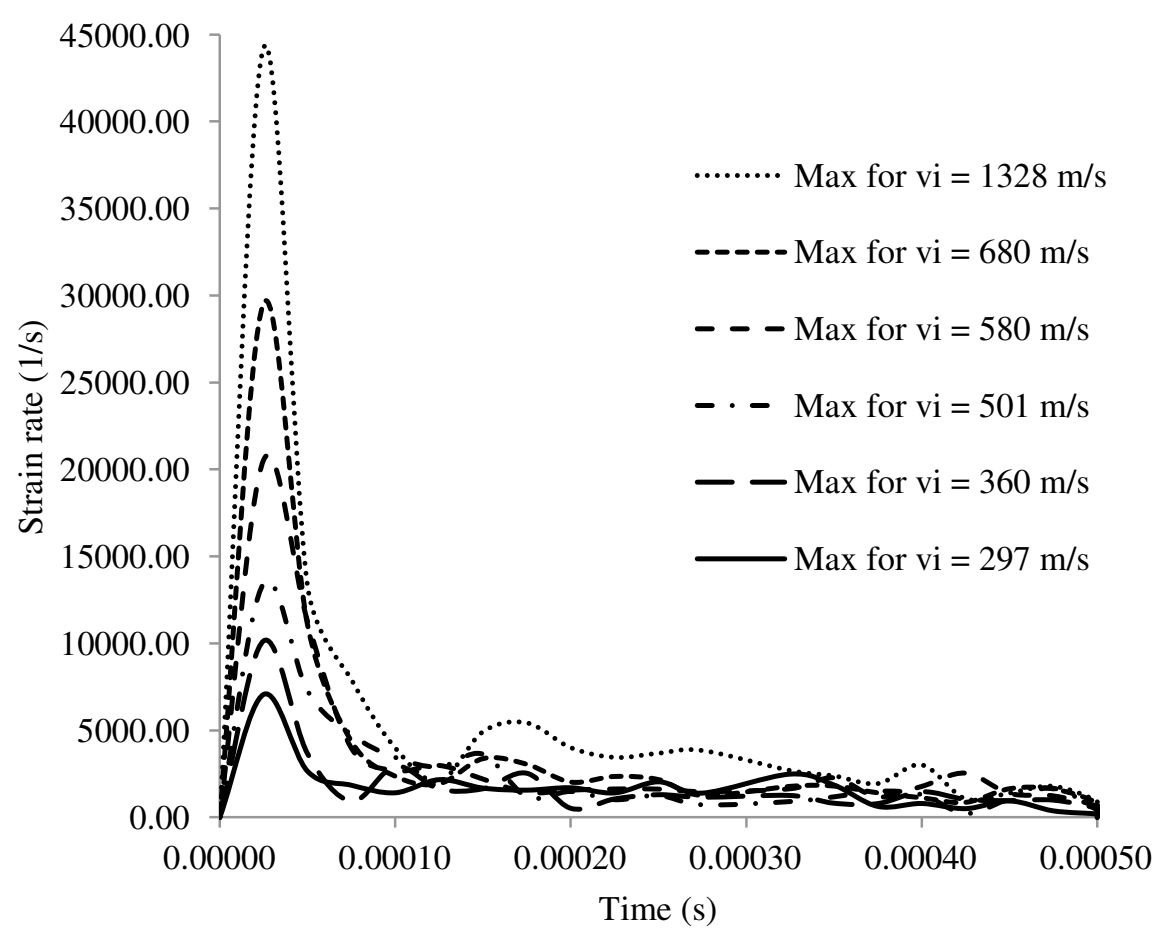

Fig. 27 Strain rates developed for all zero-obliquity FSP impact simulations

The strain rates in the sub-ordinance and ordinance velocity regime $(\mathrm{Vi}=50-1300 \mathrm{~m} / \mathrm{s})$ range between 10 and 104 [21]. This is represented well in the simulations for all velocities. There is an intense spike in strain rate in the elements at the impact interface with a subsequent attenuation resulting from the slowing of the FSP as it penetrates the cable. The effect on the material at this strain rate is viscous flow with strength still remaining significant, hence plasticity and work hardening is still valid [21]. Above a strain rate of 104fluid behaviour of the material may be more dominant and a different method of modelling may be more appropriate.

On impact, the transformation of the fragment's kinetic energy into work following the impact is a complex process. The major contributions to the total energy balance are discussed here with output from the simulations. The balance consists of a number of parts. One part of the energy is absorbed in target deformations (global and local) $\left(W_{1}\right)$, another part is absorbed in localised plastic flow and failure $\left(W_{2}\right)$, while the rest is absorbed in fragment deformation $\left(W_{3}\right)$ and contact and friction $\left(W_{4}\right)$. Given fragment ricochet was observed in all cases, the rebound kinetic energy also forms part of the balance $\left(R E_{k}\right)$. Therefore, the total energy balance is written as follows in accordance with [40 and 41].

$$
\Delta E_{B}=W_{1}+W_{2}+W_{3}+W_{4}+R E_{K}
$$


An energy balance is valid if the total energy = initial energy (kinetic energy of the fragment) + external work done or in other words if the energy ratio which is total energy / (initial energy + external work) is equal to 1.0. With reference to Equation $4.3, W_{1}$ to $W_{4}$ form the external work (internal energy in the cable) and the rebound kinetic energy $\left(R E_{k}\right)$ of the fragment is deducted from the initial energy. It is clear the main contributors are the plastic work in the wires and fragment, failure of the wires at the impact zone and individual wire displacement.

Fig. 28 presents the energy balance curves for all zero-obliquity FSP impact simulations. The figures highlight how the transition of initial energy (kinetic energy of the fragment) is converted into external work done (internal energy in the cable) with the total energy balance plotted for reference. The hourglass energy was also plotted. As can be seen the hourglass energy is relatively small in all of the simulations.

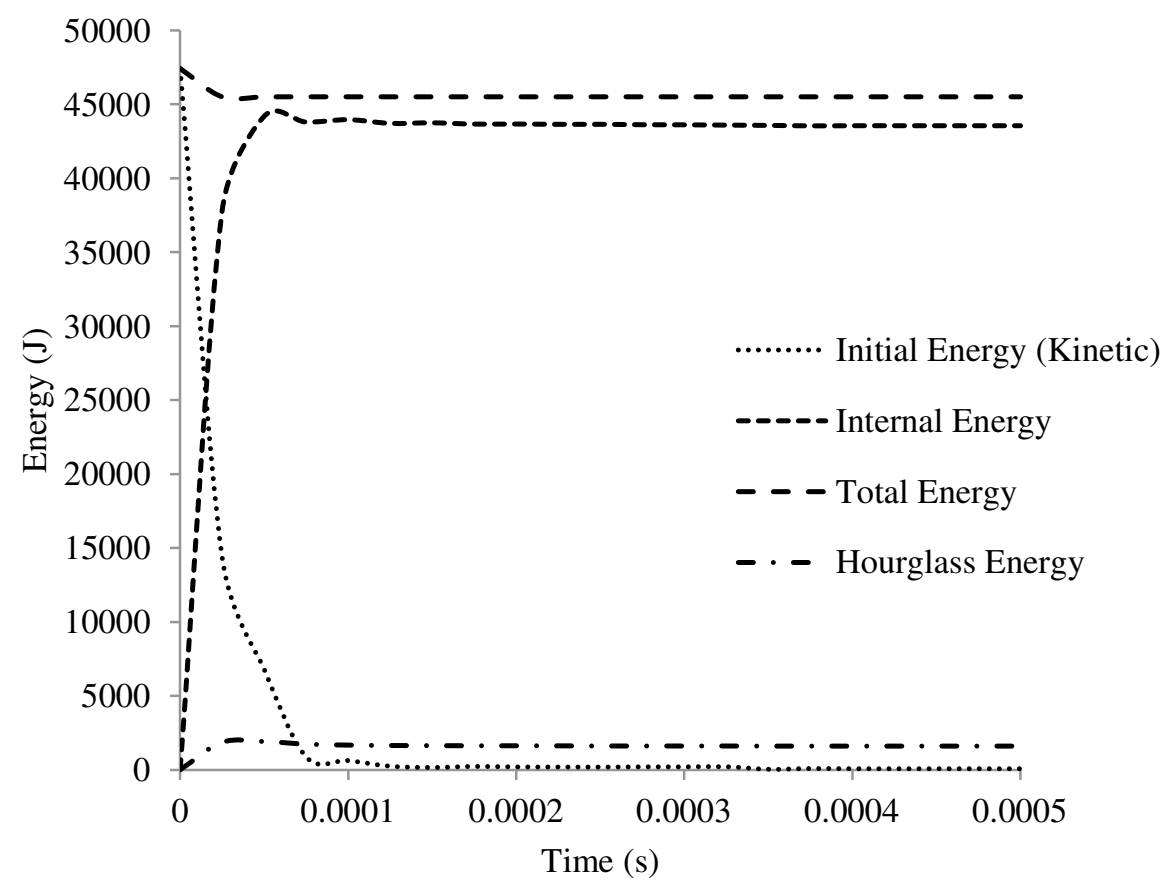

(a) Energy balance for $V_{i}=1328 \mathrm{~m} / \mathrm{s}$ (simulation 1) 


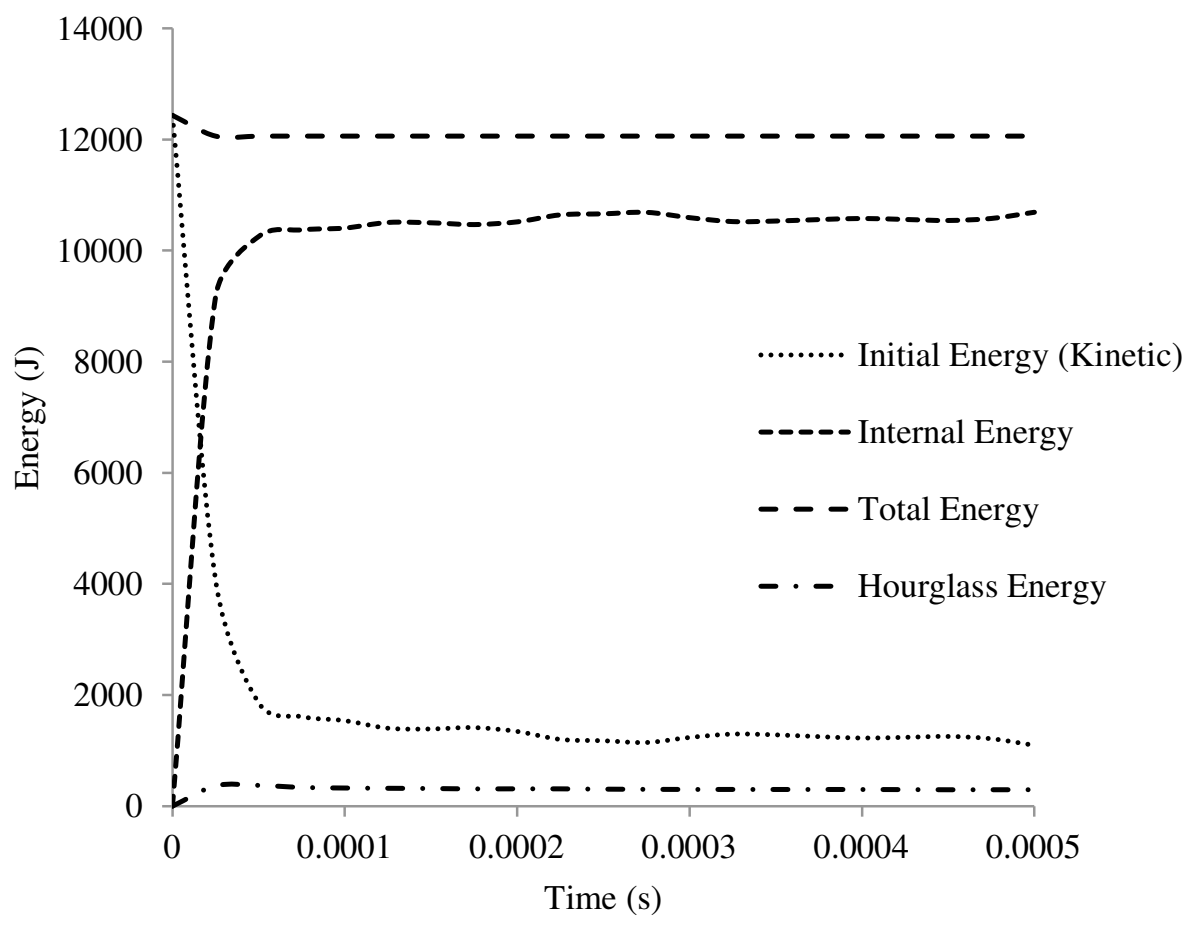

(b) Energy balance for $V_{i}=680 \mathrm{~m} / \mathrm{s}$ (simulation 2)

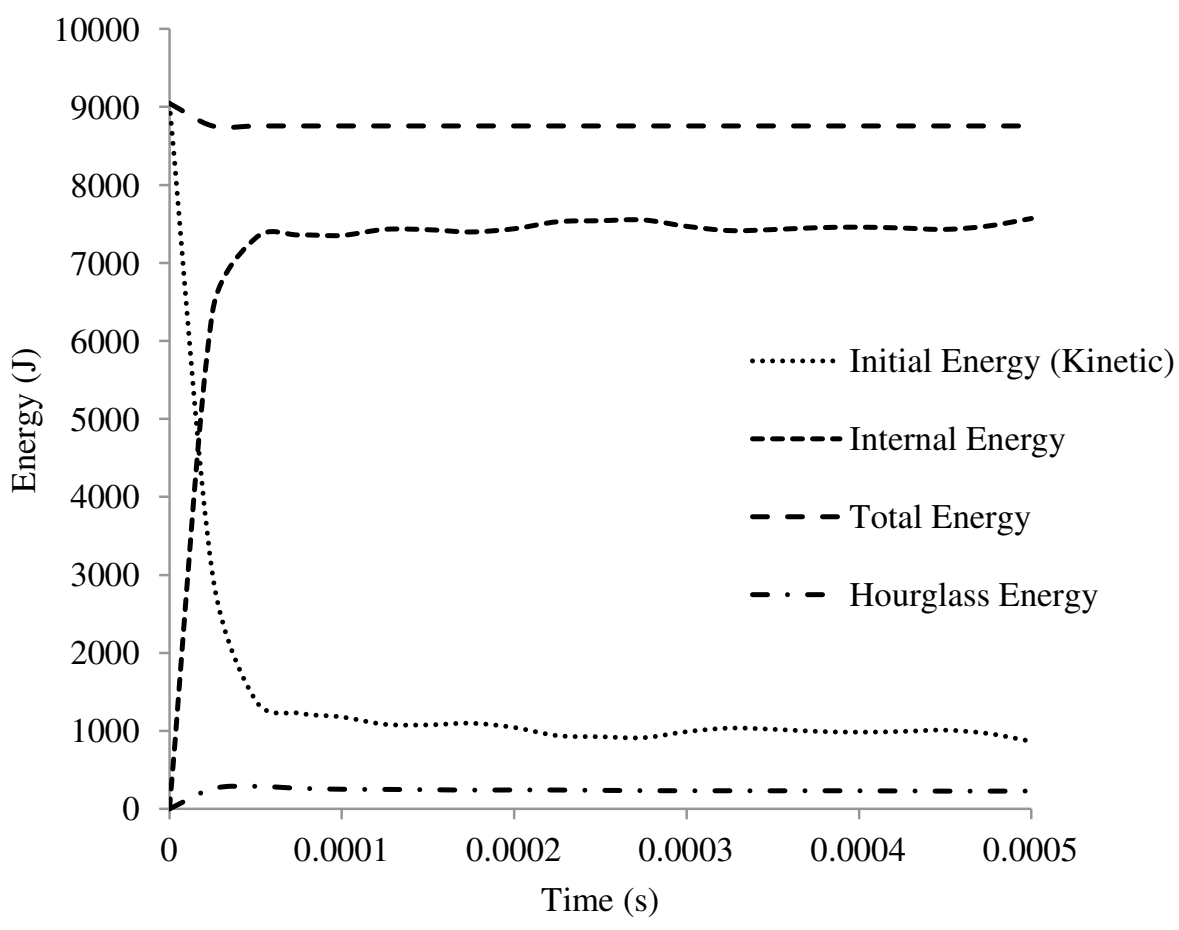

(c) Energy balance for $V_{i}=580 \mathrm{~m} / \mathrm{s}$ (simulation 3) 


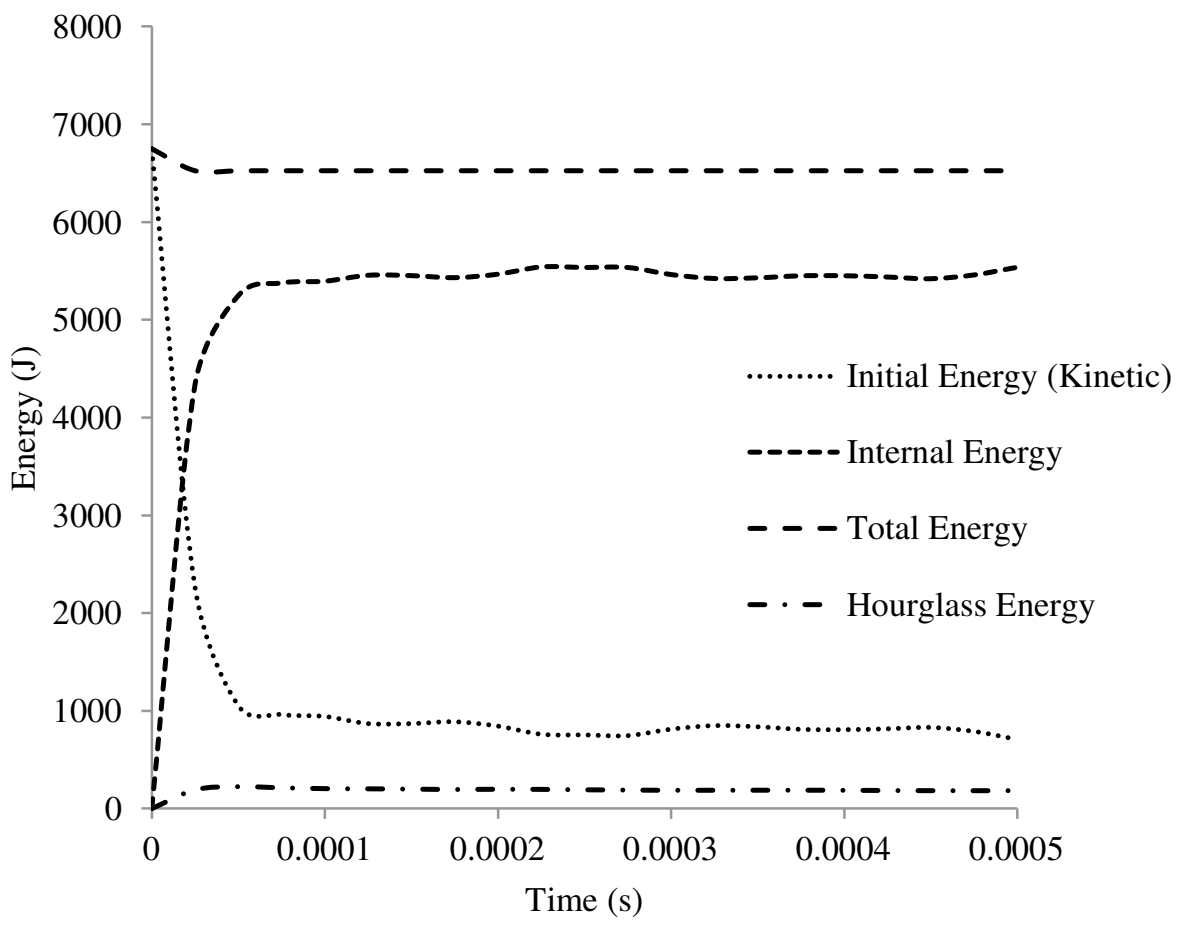

(d) Energy balance for $V_{i}=501 \mathrm{~m} / \mathrm{s}$ (simulation 4)

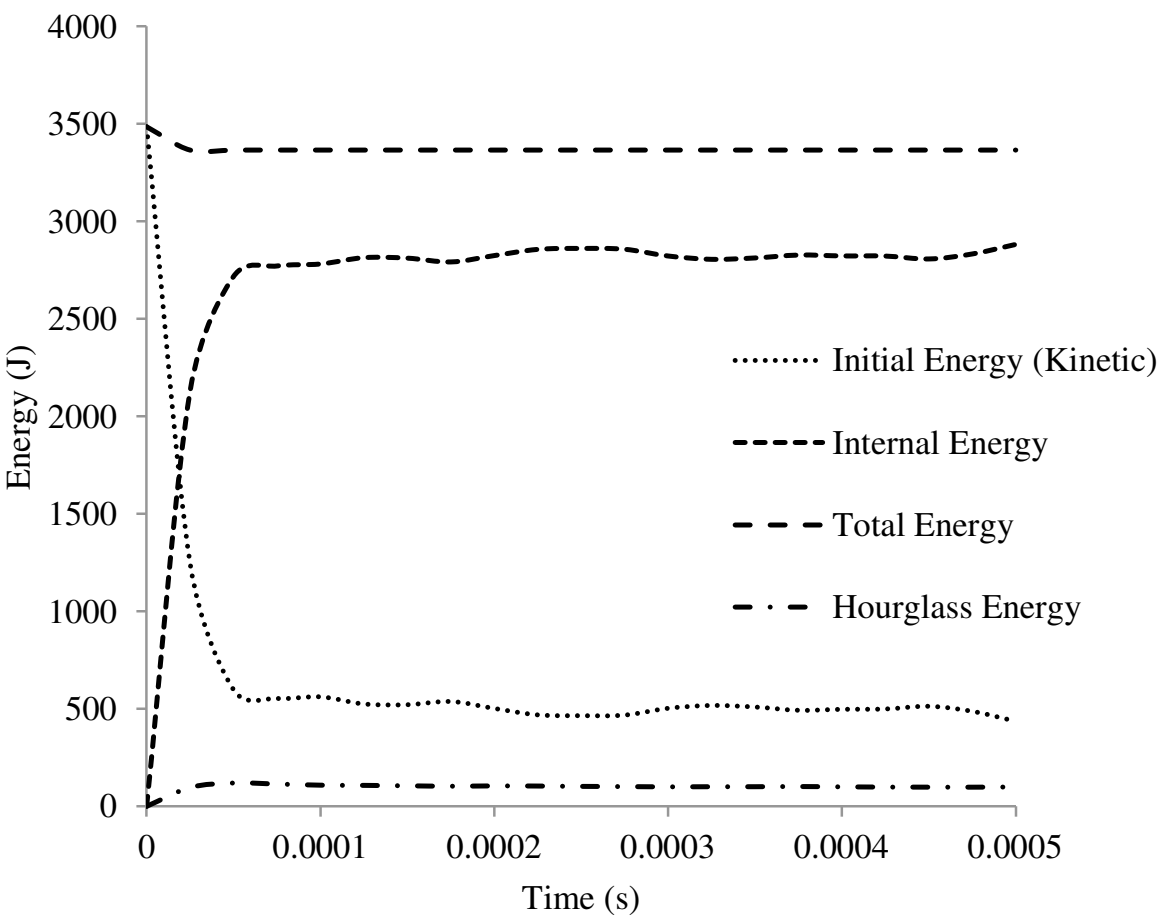

(e) Energy balance for $V_{i}=360 \mathrm{~m} / \mathrm{s}$ (simulation 5) 


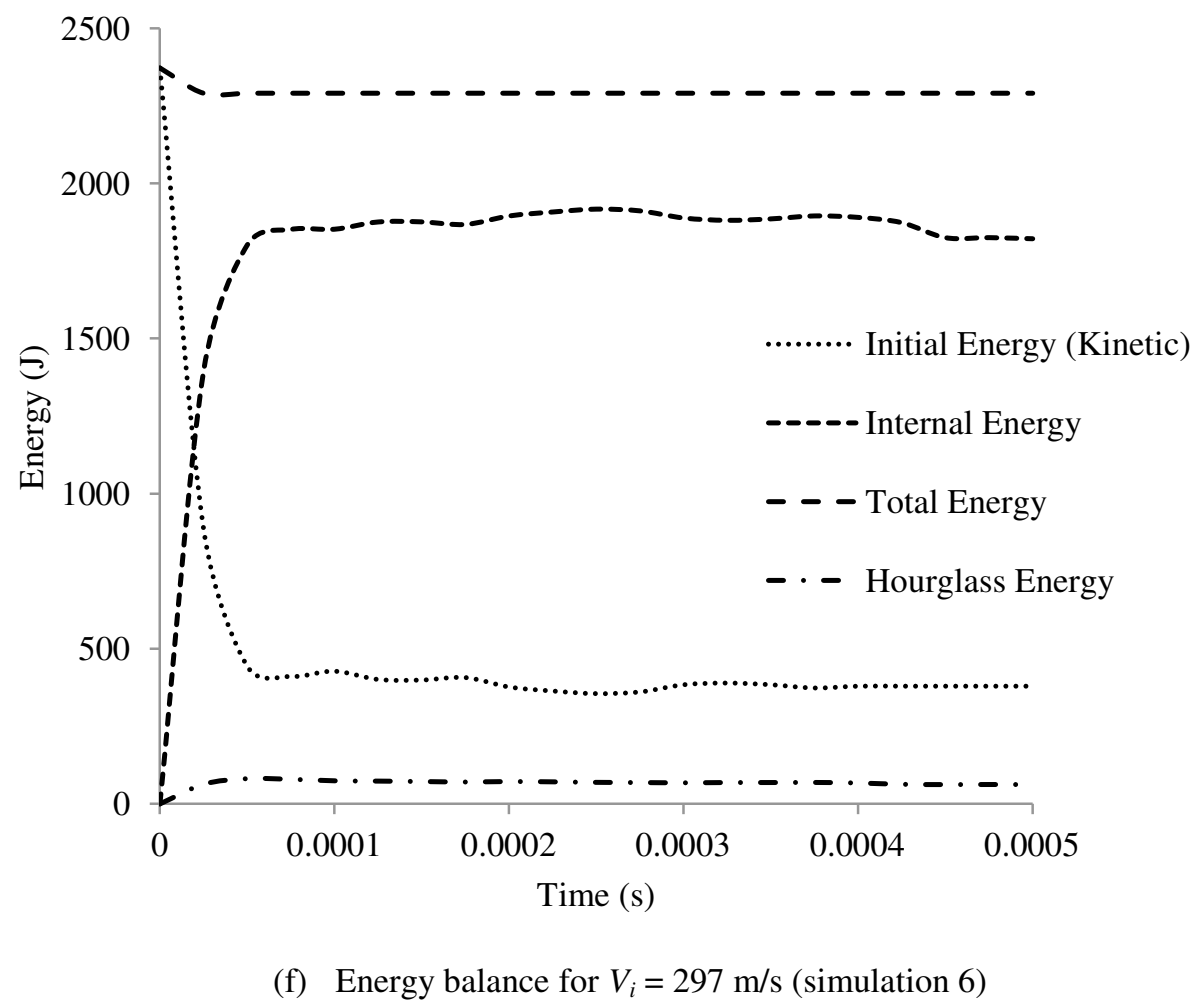

Fig 28 Energy absorption plots for all zero-obliquity FSP impact velocities

As is seen from Fig. 28(a) for $V_{i}=1328 \mathrm{~m} / \mathrm{s}$ all of the fragment's kinetic energy is transferred into internal energy (external work done in the cable). Fig. 28(b-f) display greater residual kinetic energies than that for $V_{i}=1328 \mathrm{~m} / \mathrm{s}$. During these simulations plastic flow, wire failure, extensive fragment deformation and horizontal wire splay was much less pronounced. In all simulations the energy balance is very close to unity with minor losses resulting from element hourglassing.

\subsubsection{Oblique impact simulation}

Fig. 29 shows the cable with damage obtained from numerical simulation of the $45^{\circ}$ oblique FSP impact. The fringes represent regions of high plastic strain. 


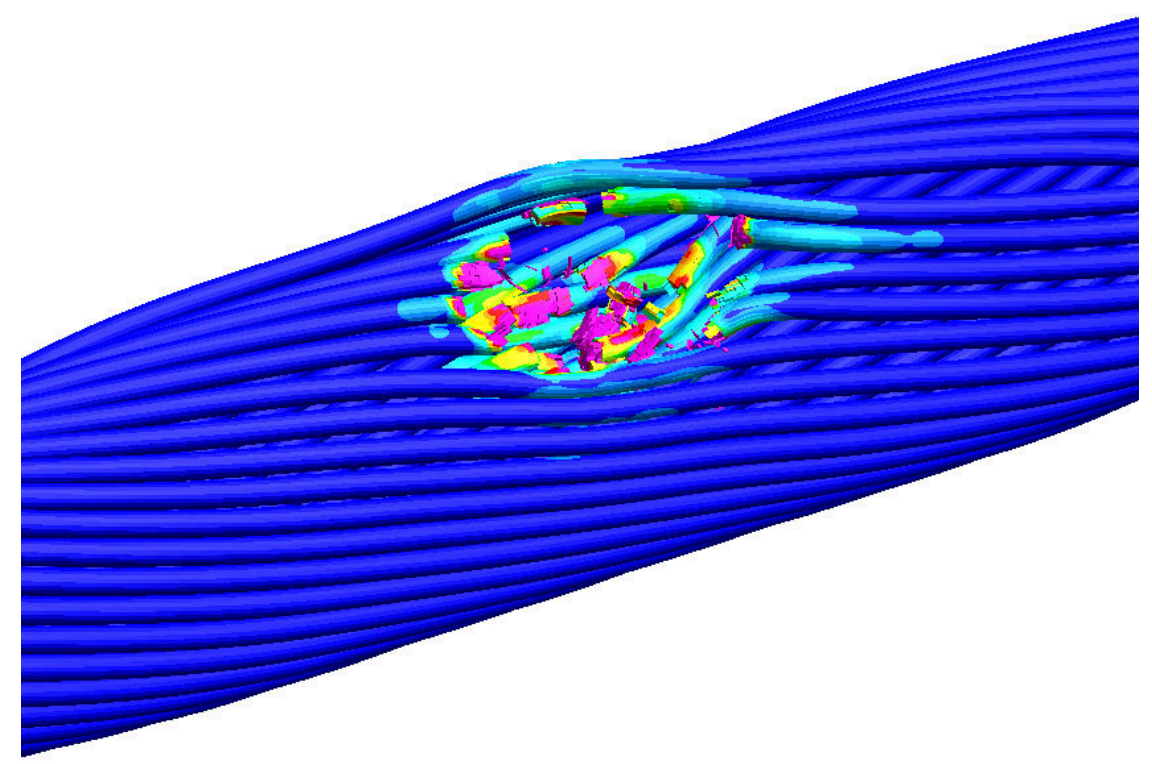

Fig. 29 The predicted cable damage for $V_{i}=640 \mathrm{~m} / \mathrm{s} @ 45^{\circ}$ impact angle (simulation 7)

At an impact angle of $45^{\circ}$ the fragment induces a drag in the wires on the periphery as observed in the testing. The simulation was terminated at the point at which fragment rebound occurred and therefore Fig. 30 compares well with Fig. 9 in Section 3. Allowing the simulation to run for a longer time period would allow greater splaying of the periphery wires as is shown in Fig. 9(e). Allowing longitudinal wire translation at the ends of the model enabled periphery wire dragging to be captured in the simulation. As with all of the zero-obliquity FSP impact simulations, the plasticity and resulting damage was localised at the impact zone. The fragment penetrated the first layer of wires as was observed in the oblique impact test and was then deflected from the cable due to the impact angle. This is shown in Fig. 30 from a side on impact view.
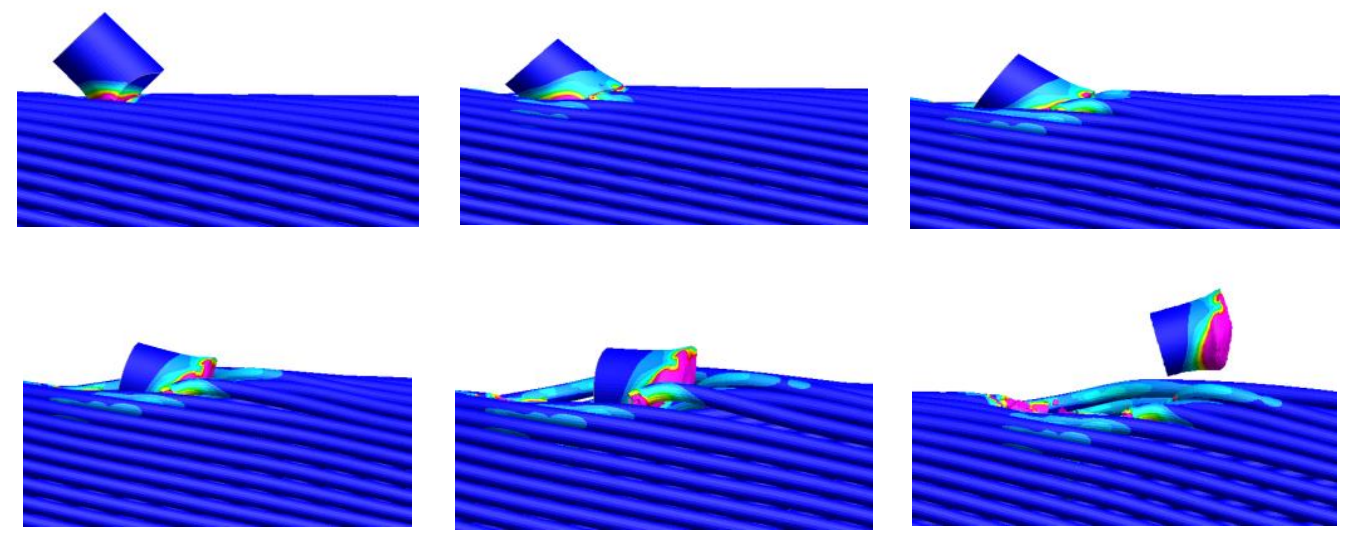

Fig. 30 Numerical simulation stills for $V_{i}=640 \mathrm{~m} / \mathrm{s} @ 45^{\circ}$ impact angle @ $45^{\circ}$ impact angle (simulation 7) 
The individual wire failure mechanisms at the impact zone were also in good agreement with that observed in the testing.

\section{Residual Cable Capacity Estimation}

The residual load carrying capacity of damaged cables is a key parameter when considering the overall structural robustness of a cable supported structure in the event of a blast. In the absence of physically subjecting the damaged cables to load-extension tests, a preliminary estimation of the residual load carrying capacity is presented here. It is based on the reduced cross-sectional area of the cable after impact using Equation 2.4 in Section 2. The cable damage is quantified by the fragment penetration depth, the number of wire layers penetrated and the number of totally fractured and heavily indented wires. Fig. 31 shows the fragment penetration depth plotted against fragment impact velocity for both the numerical work and experimental testing.

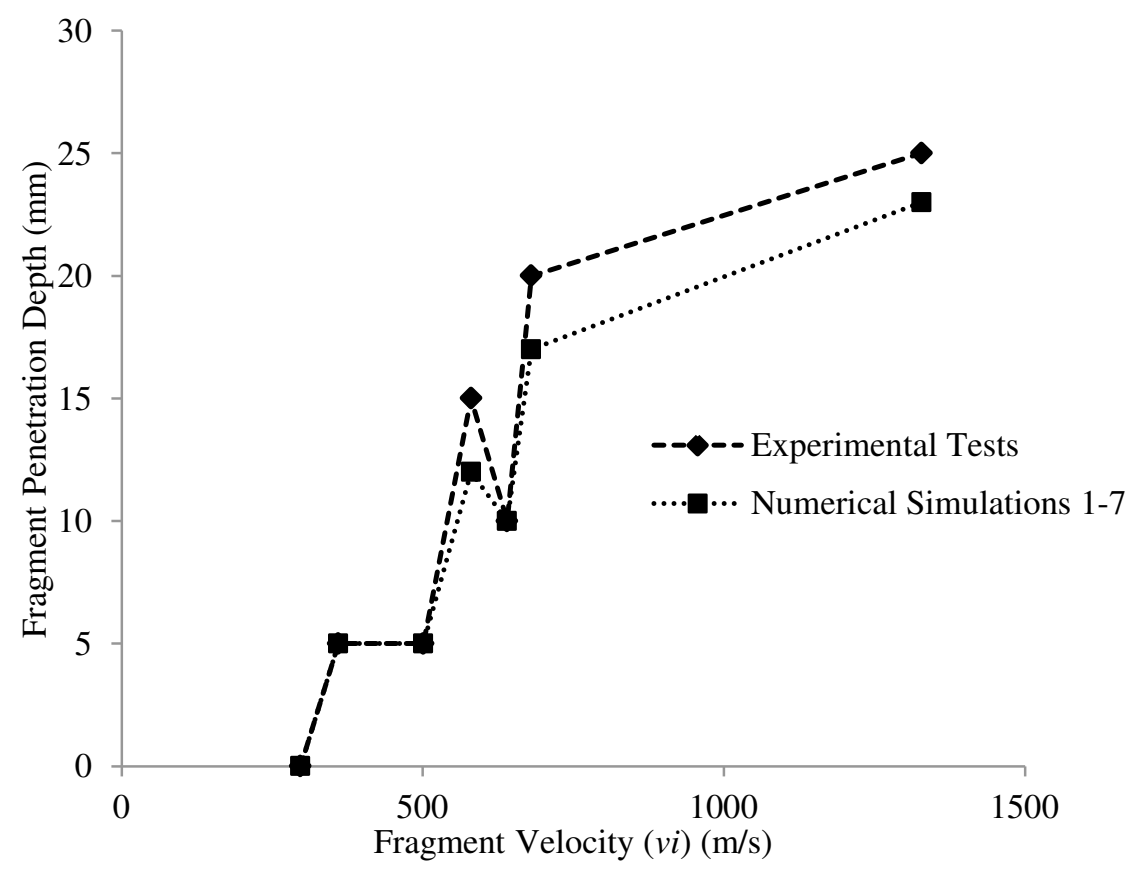

Fig. 31 The effects of impact velocity on fragment penetration depth

Good agreement can be seen in the results with slight under-predictions of the fragment penetration depth for $V_{i}=580 \mathrm{~m} / \mathrm{s}, 680 \mathrm{~m} / \mathrm{s}$ and $1328 \mathrm{~m} / \mathrm{s}$. The number of layers penetrated was the same in the simulations and tests for all velocities. However, the wire indentation and subsequent loss of wire cross-sectional area was more significant in the tests than in the simulations. This is shown in Fig. 32 were the number of totally fractured and heavily indented wires $N_{d}$ is compared to the experimental testing as described in Section 3. 


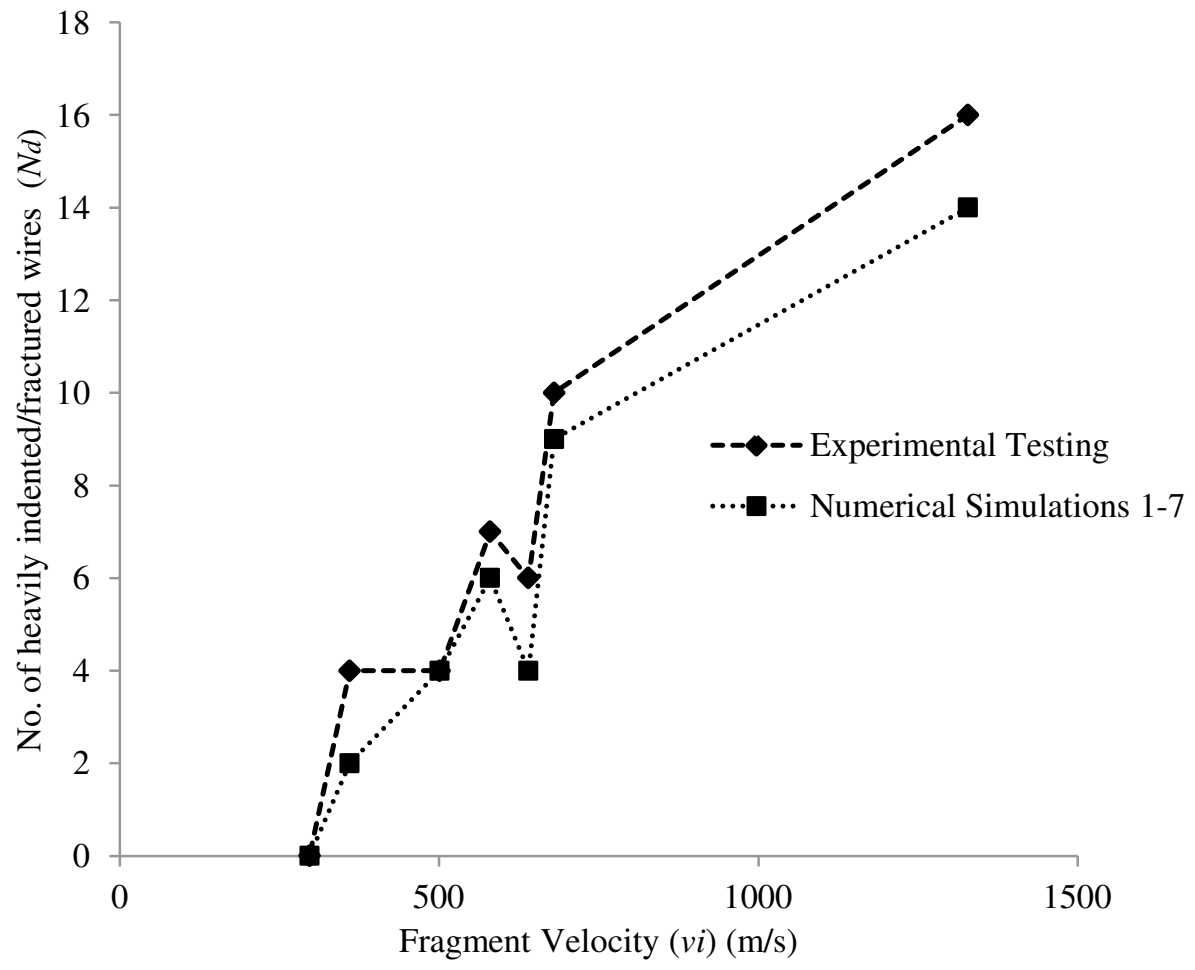

Fig. 32 The effects of impact velocity on the number of totally fractured and heavily indented wires.

Based on Fig. 32, the residual load carrying capacity was derived using Equation 2.4 and plotted in Fig 33. As is seen, there is a general reduction in load carrying capacity with an increase in fragment impact velocity and subsequent damage to the cable. The impact angle of $45^{\circ}$ at $V_{i}=640 \mathrm{~m} / \mathrm{s}$ results in less damage than $V i=580 \mathrm{~m} / \mathrm{s}$ at $0^{\circ}$ impact angle due to the disruptive effect the angle has on the trajectory of the fragment. An important observation from Fig. 33 is that the estimated reduced breaking loads are not less than the design resistance of the cable $Z_{r d}=2100 \mathrm{kN}$ which possibly suggests that the cable would not totally rupture under the design axial load (which would also have partial safety factors applied to it) after such an impact occurs. However, this is based on the assumption that Equation 2.4 is valid and the load acting in the cable at the point of and after impact is static.

Global momentum transfer was not a dominant energy dissipation mechanism in the tests and given the focus was on cable damage at the impact zone. The overall damage and wire splay zone was measured along the length of the cable samples after testing as described in Section 3. In reality, a $60 \mathrm{~mm}$ diameter spiral strand cable in a structural system would be in excess of the length tested in the present study, especially when used for the applications of concern in the present study. If an entire cable length was modelled then a more computationally efficient multi-scale model would be required. This could be achieved by attaching more simplified and cost effective 1D cable elements to the top and bottom of the detailed model with appropriate boundary conditions. Using a shorter cable length results in computational 
time reductions and more efficient and practical run-times. However, it does result in quicker stress buildups at the impact zones due to stress wave reflection at the cable ends. As a result, in a longer length cable, global momentum transfer may be greater and given the stress wave would have further distance to travel to the cable-end terminations the build-up of stress is likely to be less and hence the damage may be reduced. The absence of cable tension is also likely to have an effect on the overall damage sustained and resulting response on the overall global structural system. For high-energy events such as the detonation of an explosive device, considerable dynamic tension loads may also be induced in the cable resulting in further damage or even total rupture. Other considerations to make in future research would be multiple fragment impacts on the same cable and damage sustained in neighbouring cables from such impacts. Nevertheless, the minor discrepancies observed in the numerical results demonstrate the potential of the developed numerical model to estimate cable impact damage.

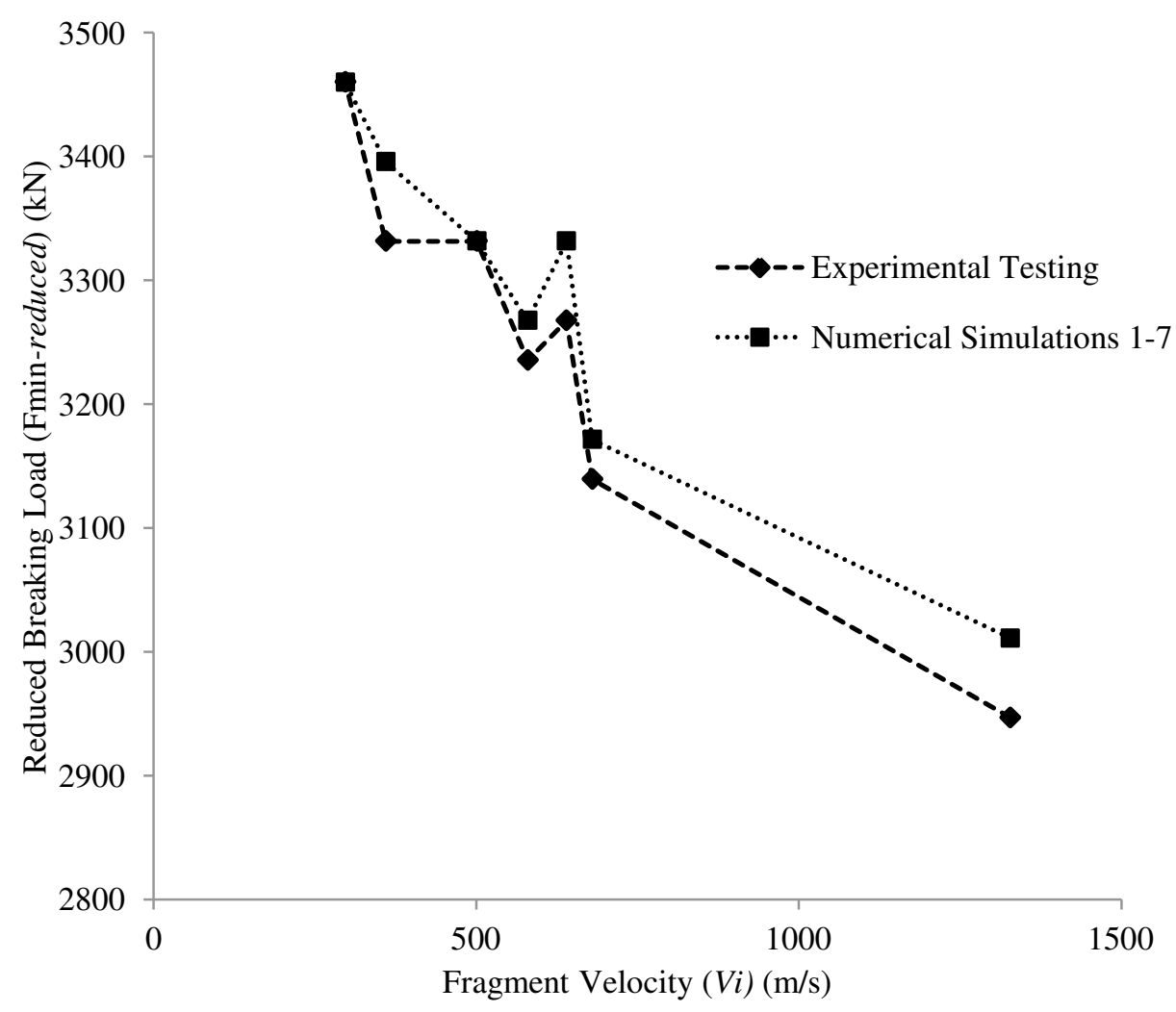

Fig. 33 An estimation of the effects of impact velocity on the minimum breaking load of the cable

\section{Conclusions}

In this paper, the responses of un-tensioned high strength steel spiral strand cables subjected to highvelocity fragment impact have been presented and discussed. It was found that for fragment impact velocities between 200 and $1400 \mathrm{~m} / \mathrm{s}$ the fragment penetration depth was less than half of the cable diameter demonstrating a considerable amount of resilience to fragment impact. Complex full 3D finite element 
models were also developed, considering the topology of the cable, complicated wire-to-wire contact conditions, and realistic material constitutive laws and fracture criterion. The numerical results were carefully compared with the laboratory impact tests, in terms of global cable response, localised damage area, fragment penetration depth, and estimated residual breaking loads. Albeit minor discrepancies were observed, the numerical results compared reasonably well with those obtained in the experimental testing, demonstrating the potential use of such models in structural design and parametric assessments of the robustness cable supported structural systems to blast fragmentation impact.

\section{Acknowledgments}

This study is funded by UK EPSRC and ARUP through a CASE Award (No. CASE/CAN/07/107). The cables tested were provided by Bridon International Ltd and their kind contributions are highly appreciated.

\section{References}

[1] Ghoreishi S.R. Messager, T. Cartraud, P. Davies, P., 2007. Validity and limitations of linear analytical models for steel wire strands under axial loading, using a 3D FE model. International Journal of Mechanical Sciences, 49, pp.1251-1261.

[2] Starossek, U., 2007. Disproportionate collapse: a pragmatic approach. Proceedings of the Institution of Civil Engineers: Structures and Buildings Journal, 160, pp.317-325.

[3] Starossek, U., 2008. Collapse resistance and robustness of bridges. In: Proceedings $4^{\text {th }}$ International Conference on Bridge Maintenance, Safety and Management. Seoul, Korea 13-17 July 2008.

[4] Wolff, M. Starossek, U., 2010. Cable-loss analyses and collapse behaviour of cable-stayed bridges. In: Proceedings of 5th International Conference on Bridge Maintenance, Safety and Management. Philadelphia 11-15 July 2010.

[5] Zoli, T.P. and Steinhouse, J., 2007. Some considerations in the design of long span bridges against progressive collapse. HNTB, New York.

[6] Army Research Laboratory. 2008. MIL-DTL-46593B.

[7] LSTC. LS-DYNA keyword user's manual. Version 971. Livermore, CA: Livermore Software Technology Corporation; March 2007.

[8] Walton, J.M., 1987. Contact stresses in wire rope. MPhil. Leeds: University of Leeds. 
[9] Walton, J.M., 1996. Developments in steel cables. Journal of Constructional Steel Research, 39 (1), pp.3-29.

[10] Bridon structural systems catalogue, 11/2007, Edition 3.

[11] British Standards Institution. 2006. BS EN 1993-1-11:2006, Eurocode 3: Design of steel structures Part 1-11: Design of structures with tension components. London: BSI.

[12] British Standards Institution. 2006. UK National Annex to BS EN 1993-1-11:2006, Eurocode 3: Design of steel structures - Part 1-1: Design of structures with tension components. London: BSI.

[13] STANAG 4569, May 2004, "Protection Levels for Occupants of Logistic and Light Armoured Vehicles".

[14] Zukas JA, Nicholas T, Swift H, Greszczuk LB, Curran D. Impact Dynamics. New York: John Wiley \& Sons; 1982.

[15] Zukas JA, Hohler V, Jameson RL, Madrer CL, Nicholas T, Rajendran T, et al. High Velocity Impact Dynamics. New York: John Wiley \& Sons; 1990.

[16] Borvik, T. Hopperstad, O.S. Berstad, T. Langseth, M., 2001. A computational model of viscoplastcity and ductile damage for impact and penetration. European Journal of Mechanics and Solids 20, pp.685712 .

[17] Johnson, G.R. Cook, W.H., 1983. A constitutive model and data for metals subjected to large strains, high strain rates and high temperatures. In: Proceedings of the 7th International Symposium on Ballistics. Hague.

[18] Borvik T, Hopperstad OS, Berstad T, Langseth M. Perforation of $12 \mathrm{~mm}$ thick steel plates by $20 \mathrm{~mm}$ diameter projectiles with blunt, hemispherical and conical noses, part II: numerical simulations. International Journal of Impact Engineering 2002; 27: 37-64.

[19] Borvik T, Hopperstad OS, Langseth M, Malo KA. Effect of target thickness in blunt projectile penetration of Weldox 460 E steel plates. International Journal of Impact Engineering 2003; 23: 413 64. 
[20] Dey S, Borvik T, Hopperstad OS, Leinum JR, Langseth M. The effect of target strength on the perforation of steel plates using three different projectile nose shapes. International Journal of Impact Engineering 2004; 30: 1005-38.

[21] Dey S. High-strength steel plates subjected to projectile impact: An experimental and numerical study. Dr. Ink Thesis. Norwegian University of Science and Technology, 2004.

[22] Dey S, Borvik T, Hopperstad OS, Langseth M. On the influence of fracture criterion in projectile impact on steel plates. Computational Materials Science 2006; 38: 176-191.

[23] Borvik T, Dey S, Clausen A.H. Perforation resistance of five different high-strength steel plates subjected small-arms projectiles. International Journal of Impact Engineering 2009; 36: 948-964

[24] Cockcroft M.G. and Latham, D.J., 1968. Ductility and the workability of metals. Journal of the Institute of Metals, 96, pp.33-39.

[25] Bao, Y. and Wierzbicki, T., 2004. A comparative study on various ductile crack formation criteria. Journal of Engineering Materials and Technology, 126, pp.314-24.

[26] Bao, Y. and Wierzbicki, T., 2004. On fracture locus in the equivalent strain and stress triaxiality space. International Journal of Mechanical Sciences, 46, pp.81-98.

[27] Teng, X. Wierzbicki, T. Couque, H., 2007. On the transition from adiabatic shear banding to fracture. Mechanics and Materials, 39, pp.107-25.

[28] Hosford, W.F. and Caddell, R.M., 1993. Metal forming (Mechanics and metallurgy). New Jersey: Prentice Hall, Inc.

[29] Galvez, F. Atienza, M.M. Ruiz, J. Elices, M. 2002. The effect of strain rate on steel wires failure during cold during. In Proceedings of: Biennial Conference on Fracture - EC14. Cracow, Poland, 2002.[30] Meyers, M.A., 1994. Dynamic behaviour of materials. New York: John Wiley and Sons.

[31] Tillotson, J H., 1962. Metallic Equations of State for Hypervelocity Impact. General Atomic GA3216.

[32] Royce, E B., 1971. Gray, A Three Stage Equation of State for Metals. Lawrence Livermore National Laboratories, USA. 
[35] Flanagan, D.P. and Belytschko, T., 1981. A Uniform Strain Hexahedron and Quadrilateral and Orthogonal Hourglass Control. International Journal of Numerical Methods in Engineering, 17, pp.679-706.

[36] Ravid, M. and Bodner, S.R., 1983. Dynamic perforation of visco-plastic plates by rigid projectiles. International Journal of Engineering Science, 21 (6), pp.577-91.

[37] Yu, Y. Chen, Z. Liu, H. Wang, X., 2014. Finite element study of behaviour and interface force conditions of seven-wire strand under axial and lateral loading. Journal of Construction and Building Material, 66, pp.10-18.

[38] Jiang, W.G. Yao, M.S. Walton, J.M., 1999. A concise finite element model for simple straight wire rope strand. International Journal of Mechanical Sciences, 41 (2), pp.143-61.

[39] Jiang, W.G. Yao, M.S. Walton, J.M., 2000. A concise finite element model for three-layered straight wire rope. International Journal of Mechanical Sciences, 41 (1), pp.63-89.

[40] Borvik, T. Hopperstad, O.S. Langseth, M. Malo, K.A., 2002a. Perforation of $12 \mathrm{~mm}$ thick steel plates by $20 \mathrm{~mm}$ diameter projectiles with blunt, hemispherical, and conical noses, Part I: experimental study. International Journal of Impact Engineering, 271, pp.19-25.

[41] Borvik, T. Hopperstad, O.S. Langseth, M. Malo, K.A., 2002b. Perforation of $12 \mathrm{~mm}$ thick steel platesby $20 \mathrm{~mm}$ diameter projectiles with blunt, hemispherical, and conical noses, Part II: numerical simulations. International Journal of Impact Engineering, 271, pp.37-64. 